
Jefferson de Souza Pinto

Rafael dos Reis Lima de Andrade

Ana Cristina Gobbo Cesar

\section{UTILIZAÇÃO DO MÉTODO DE RESOLUÇÃO DE PROBLEMAS DE POLYA PARA ENSINAR MATEMÁTICA}

Belo Horizonte

Poisson

2018 
Editor Chefe: Dr. Darly Fernando Andrade

\section{Conselho Editorial}

Dr. Antônio Artur de Souza - Universidade Federal de Minas Gerais

Dra. Cacilda Nacur Lorentz - Universidade do Estado de Minas Gerais

Dr. José Eduardo Ferreira Lopes - Universidade Federal de Uberlândia

Dr. Otaviano Francisco Neves - Pontifícia Universidade Católica de Minas Gerais

Dr. Luiz Cláudio de Lima - Universidade FUMEC

Dr. Nelson Ferreira Filho - Faculdades Kennedy

\section{Dados Internacionais de Catalogação na Publicação (CIP)}

\section{P659}

PINTO. Jefferson de Souza; ANDRADE, Rafael dos Reis Lima de; CESAR, Ana Cristina Gobbo - Utilização do método de resolução de problemas de polya para ensinar matemática. Belo Horizonte, Editora Poisson, 2018.

$57 p$.

Formato: PDF

ISBN : 978-85-7041-027-5

DOI : $10.5935 / 978-85-7041-027-5.2018$ B001

Modo de acesso: World Wide Web

Inclui bibliografia

1. Ensino 2. Matemática 3. Aprendizagem

4. Ensino Médio I. Título

O conteúdo dessa obra e seus dados em sua forma, correção e confiabilidade são de responsabilidade exclusiva dos seus respectivos autores.

$\underline{\text { www.poisson.com.br }}$

contato@poisson.com.br 


\section{APRESENTAÇÃO}

Atualmente, os Parâmetros Curriculares Nacionais propõem que o ensino seja pautado na transversalidade, ou seja, que os temas desenvolvidos na prática educativa sejam relacionados com a realidade dos estudantes. Dentre os temas transversais indicados pelo MEC está o meio ambiente e, inserido neste, encontram-se a coleta seletiva e o descarte do lixo de forma adequada.

O Método de Resolução de Problemas de Polya é um modelo desenvolvido por George Polya, que estabelece quatro etapas a serem percorridas para que um dado problema seja resolvido: compreender o problema, planejar sua resolução, executar a resolução e verificar a solução obtida.

Com um sólido embasamento teórico em Educação Matemática, Matemática e Coleta Seletiva, Jefferson de Souza Pinto, Rafael dos Reis Lima de Andrade e Ana Cristina Gobbo Cesar apresentam sugestões de utilização do Método de Resolução de Problemas de Polya com a finalidade de ensinar matemática para estudantes do Ensino Médio. Para isso os autores fazem uso de dados relativos ao adequado descarte do lixo e à coleta seletiva pertencentes a municípios da região de Bragança Paulista, e propõem atividades didáticas com esses dados. Através de um trabalho de abordagem qualitativa e de natureza aplicada levam o leitor a ponderar sobre a influência de metodologias de ensino não tradicionais como o Método da Resolução de Problemas na aprendizagem e como o mesmo pode auxiliar os professores a superarem diversos obstáculos do ensino. Como uma das principais qualidades dos temas transversais é a interdisciplinaridade, a temática da coleta seletiva e descarte do lixo não é de uso exclusivo da matemática, pois permite integração com outras áreas de ensino.

Em resumo, esta é uma leitura indicada para docentes que desejam conhecer a Metodologia de Resolução de Problemas de Polya e que planejam trabalhar de forma transversal e interdisciplinar possibilitando um ensino mais próximo da realidade dos estudantes e educando-os também no que diz respeito à preservação do meio ambiente.

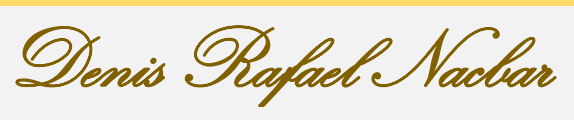

Professor da área de matemática do Instituto Federal de Educação, Ciência e Tecnologia de São Paulo, campus Bragança Paulista. Doutor e mestre em Ciência e Tecnologia de Materiais pela Universidade Estadual Paulista Júlio de Mesquita Filho. Graduação em Licenciatura em Matemática pela Universidade Estadual Paulista Júlio de Mesquita Filho. 


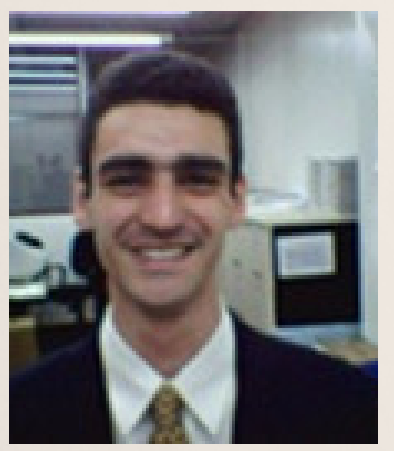

\section{Jefferson de Souza Pinto}

Pós-doutor em Engenharia Mecânica pela Universidade Estadual de Campinas (2014, 2016 e 2018). Doutor (2012) com pesquisa na área de Gestão de Projetos e Mestre (2004) em Engenharia Mecânica pela Universidade Estadual de Campinas. Especialista em Gestão de Processos Industriais pela Universidade Estadual de Campinas (2002). Administrador de Empresas com habilitação em Comércio Exterior pela Universidade São Francisco (1999).

Pesquisador colaborador e professor colaborador da Faculdade de Engenharia Mecânica da Universidade Estadual de Campinas. Atualmente é professor concursado do Instituto Federal de Educação, Ciência e Tecnologia de São Paulo (IFSP), Campus Bragança Paulista. Possui experiência e pesquisas nas áreas de Empreendedorismo, Gestão da Produção e Operações, Gestão da Qualidade, Gestão da Cadeia de Suprimentos e Gestão de Projetos. Detém mais 27 artigos científicos publicados em periódicos nacionais e internacionais correlacionados nas áreas mencionadas.

\section{Rafael dos Reis Lima de Andrade}

Graduado em Licenciatura em Matemática pelo Instituto Federal de Educação, Ciência e Tecnologia de São Paulo, Campus Bragança Paulista. Foi monitor na área de geometria plana e analítica, vetores, fundamentos da matemática e desenho geométrico. Participou do Programa Institucional de Bolsa de Iniciação à Docência (PIBID). Professor de matemática em diversas escolas e programas..
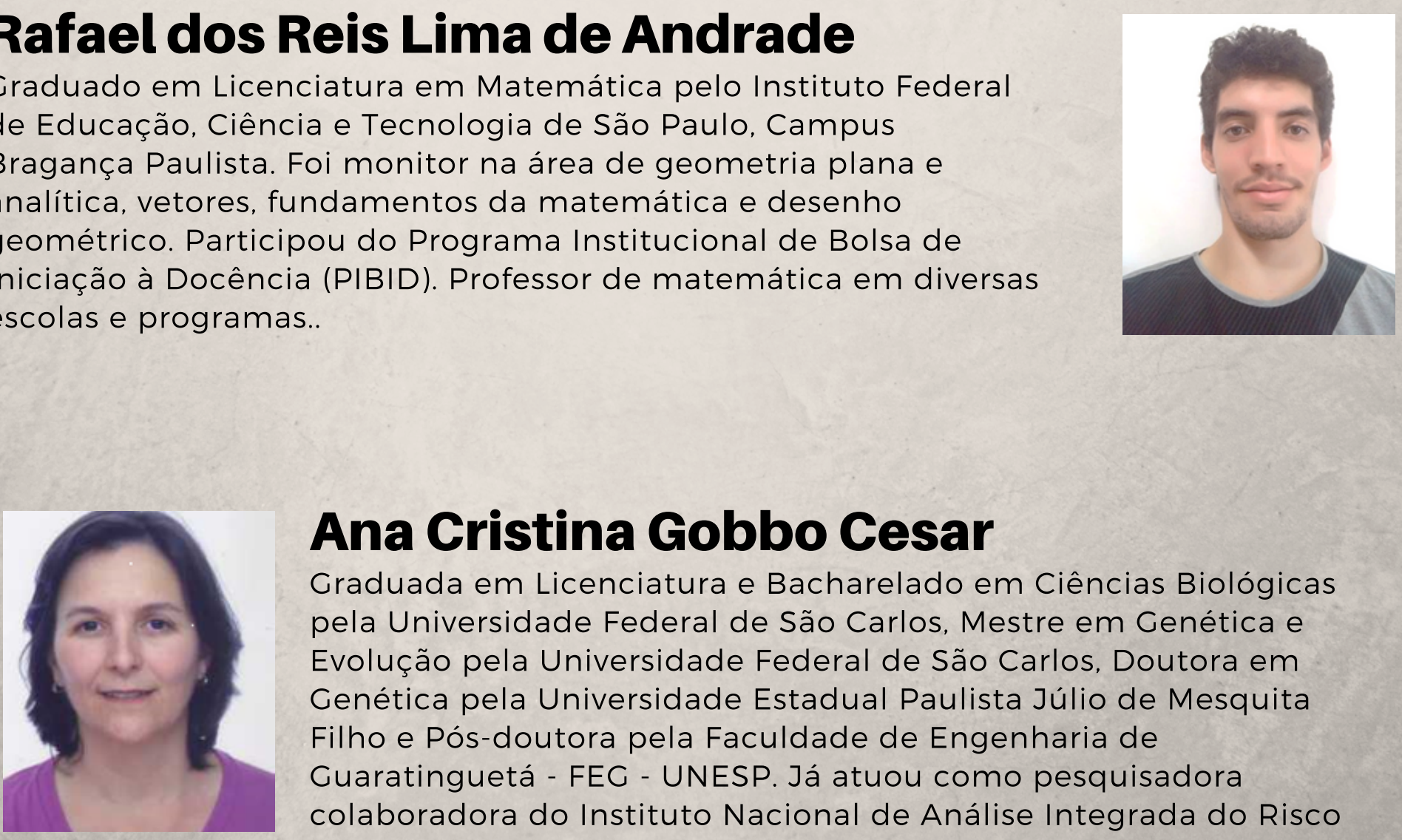

\section{Ana Cristina Gobbo Cesar}

Graduada em Licenciatura e Bacharelado em Ciências Biológicas pela Universidade Federal de São Carlos, Mestre em Genética e Evolução pela Universidade Federal de São Carlos, Doutora em Genética pela Universidade Estadual Paulista Júlio de Mesquita Filho e Pós-doutora pela Faculdade de Engenharia de Guaratinguetá - FEG - UNESP. Já atuou como pesquisadora colaboradora do Instituto Nacional de Análise Integrada do Risco Ambiental (INAIRA) e professora na Universidade de Taubaté (UNITAU) na graduação e pós-graduação, no EAD e no PIBID Diversidade (Capes). Atualmente, atua como professora no Instituto Federal de Educação, Ciência e Tecnologia de São Paulo, Campus Bragança Paulista. Desenvolve pesquisa sobre biomonitoramento de ambientes aquáticos e sobre o impacto dos poluentes atmosféricos na saúde humana. 


\section{SUMÁRIO}

\begin{tabular}{|l|l|c|}
\hline 1 & INTRODUÇÃO & 8 \\
\hline 2 & FUNDAMENTAÇÃO TEÓRICA & 11 \\
\hline 3 & MÉTODO & 23 \\
\hline 4 & ANÁLISE DE DADOS & 26 \\
\hline 5 & CONCLUSÕES & 47 \\
\hline 6 & REFERÊNCIAS & 50 \\
\hline 7 & APÊNDICES & 53 \\
\hline
\end{tabular}




\section{Nomenclaturas}

\begin{tabular}{|c|c|}
\hline CEP & Cômite de Ética em Pesquisa \\
\hline DCN & Diretrizes Curriculares Nacionais. \\
\hline EM & Ensino Médio. \\
\hline IBGE & Instituto Brasileiro de Geografia e Estatística. \\
\hline LDB & Lei de Diretrizes e Bases. \\
\hline PCN & Parâmetros Curriculares Nacionais. \\
\hline MEC & Ministério da Educação. \\
\hline MRP & Método de Resolução de Problemas. \\
\hline PCN & Parâmetros Curriculares Nacionais. \\
\hline PCNEM & Parâmetros Curriculares Nacionais do Ensino Médio. \\
\hline PMCS & Plano Municipal da Coleta Seletiva de Atibaia. \\
\hline PMGIRS & Plano Municipal de Gestão Integrada de Resíduos Sólidos. \\
\hline PMSB & Plano Municipal de Saneamento Básico. \\
\hline PNRS & Política Nacional de Resíduos Sólidos. \\
\hline PNSB & Política Nacional de Saneamento Básico. \\
\hline SAAE & Saneamento Ambiental Atibaia. \\
\hline SISNAMA & Sistema Nacional de Meio Ambiente \\
\hline SMMA & Secretaria Municipal de Meio Ambiente. \\
\hline SNVS & Sistema Nacional de Vigilância Sanitária \\
\hline SUASA & Sistema Unificado de Atenção à Sanidade Agropecuária \\
\hline
\end{tabular}




\section{Capítulo 1}

Introdução 


\section{INTRODUÇÃO}

A escola carece cada vez mais de uma aproximação entre a realidade dos estudantes e do que ocorre a sua volta com os conteúdos ensinados nas escolas, para que o aprendizado possa colaborar e interagir com o dia-a-dia dos cidadãos. Um cidadão consciente de valores e armado de conhecimento transforma sua realidade e, consequentemente o mundo a sua volta.

Assim, este estudo desenvolveu como alternativa aos profissionais da área de educação, um modo de utilizar o Método de Resolução de Problemas (MRP) de Polya no contexto da coleta seletiva, com a intenção, entre outras, de aproximar conteúdos matemáticos de uma realidade que cerca a sociedade atual e, consequentemente os estudantes. Além disso, o MRP trabalha principalmente a autonomia de raciocinar sobre as soluções.

Dentro da sala de aula também podem ser trabalhados diversos valores para ajudar os alunos na sua formação moral e ética. Dentre os valores, o mais valioso é a autonomia de raciocínio. Com isto, os alunos conseguem questionar o mundo a sua volta e transformá-lo na medida de suas concepções e limitações. Assim, poderá contribuir com a integração do aluno com as demais atividades escolares e com a sua própria comunidade (LDB, 1996).

Além disso, o conhecimento matemático é a principal ferramenta usada no desenvolvimento das tecnologias atuais, e que por isso molda, de maneira indireta, as relações sociais, econômicas e políticas da sociedade contemporânea. No entanto, os estudantes brasileiros apresentam muita dificuldade no domínio da Matemática. Por isso, é de vital importância a busca dos educadores de Matemática por um processo de ensino-aprendizagem mais eficiente, colaborando para que os alunos desenvolvam o domínio dos conceitos matemáticos (FERNANDES, 2010).

\subsection{CONTEXTO E JUSTIFICATIVA}

O ensino de Matemática precisa passar constantemente por mudanças para se adequar as necessidades da sociedade e consequentemente, dos estudantes. De acordo com D`Ambrósio (1989), os alunos têm uma grande dificuldade em compreender os conceitos matemáticos e, geralmente saem do sistema educacional sem o devido conhecimento para ingressar na sociedade e no mundo do trabalho. Tal dificuldade está atrelada, entre outros fatores, mas principalmente ao elemento fundamental entre o aluno e o conhecimento, o professor.

Essas adequações no processo de ensino-aprendizagem são a busca constante de qualquer professor interessado no desenvolvimento dos seus estudantes. Um recurso muito utilizado para isso é a Educação Matemática, que tem a finalidade de facilitar o aprendizado de Matemática por meio de dispositivos educacionais, como, no caso da pesquisa, atividades didáticas de Resolução de Problemas e interdisciplinaridade que aproximam os conteúdos teóricos da realidade dos alunos. Além disso, o conhecimento em Matemática também serve para intensificar o processo de aprendizagem em diversas áreas, uma vez que, a Matemática está presente no dia-a-dia e dá luz a diversos problemas, sejam eles científicos ou empíricos (LUIZ e COL, 2013).

Os professores devem mostrar aos estudantes que a Matemática não é um corpo de conceitos verdadeiros e estáticos, do qual não se dúvida ou questiona, nem mesmo preocupa-se em compreender porque funciona (D'AMBROSIO, 1989). Uma vez que eles acreditam que, "a solução de um problema encontrada matematicamente não estará, necessariamente, relacionada com a solução do mesmo problema numa situação real", os estudantes perdem cada vez mais a autoconfiança em sua intuição Matemática (D'AMBROSIO, 1989, p.15).

Para tanto, a educação Matemática necessita cada vez mais de métodos que melhorem sua compreensão e ofereçam ao aluno uma aprendizagem Matemática significativa. Por isso, é importante investir em métodos que encontrem em situações reais sua aplicabilidade Matemática e que promovam um ensino participativo e contextualizado (FERNANDES, 2010).

Da mesma maneira, atividades didáticas de Resolução de Problemas propõem aos estudantes desafios a serem realizados, onde os alunos devem lidar com as limitações de seus conhecimentos sobre os assuntos abordados, processo que fornece um maior significado ao aprendizado (POLYA, 1995). Segundo Clement e Terrazzan (2011, p. 87), 
No ensino de ciências e Matemática as atividades didáticas de resolução de problemas são consideradas atividades fundamentais para a promoção da aprendizagem dos alunos, pois servem para ativar o "motor do ato de pensar" (VASCONCELOS, 2007 apud CLEMENT e TERRAZAN, 2011, p.87).

Mas, resolver problemas não significa resolver exercícios, pois a resolução destes nada mais é do que prega o livro didático, um método de repetição de um contexto dado (POLYA, 1995). Utilizar o tempo com operações rotineiras aniquila o interesse e tolhe o desenvolvimento intelectual dos estudantes e é facilmente esquecido. Enquanto que o Método de Resolução de Problemas fornece aos alunos estudos consistentes dos assuntos abordados, estes que ficam por mais tempo na memória, pois exigem um esforço e um raciocínio mental para serem adquiridos (POLYA, 1995).

Assim, a tendência será que a aula expositiva com a qual os estudantes estão acostumados, em que o professor passa para o aluno aquilo que ele julga importante e em seguida procura fazer exercícios de aplicação, passe a ser abordada de uma maneira diferente, buscando tirar os alunos da dependência das regras do professor e encorajá-los a construir seus próprios conceitos (D'AMBROSIO, 1989).

Então, como a defasagem dos alunos em conceitos e conteúdos matemáticos traz prejuízo à sociedade, enquanto esses como futuros cidadãos e profissionais que deverão lidar com diversas funções sociais, que exigem o domínio de tais conhecimentos, as atividades de Resolução de Problemas se tornam uma estratégia para melhorar o aprendizado de Matemática.

Desta forma, este estudo pretende elaborar material didático para colaborar com o ensino de Matemática, usando como plano de fundo o contexto da coleta seletiva. Isto promove a interdisciplinaridade ou tema transversal, como recurso didático para aproximar as atividades de Resolução de Problemas ao contexto da coleta seletiva da Microrregião de Bragança Paulista. Para Terradas (2011, p.99), a interdisciplinaridade "é a atitude que se deve tomar para superar todo e qualquer enfoque fragmentado que ainda mantemos do mundo e da realidade que nos cerca", que aplicado no ambiente escolar, permite a aproximação de conceitos matemáticos e de outras disciplinas à realidade dos estudantes. De acordo com os Parâmetros Curriculares Nacionais (PCN, 2000), este método serve como um dispositivo educacional útil para transformar o ensino de Matemática.

O contexto da coleta seletiva foi escolhido, pois é um tema discutido atualmente tanto no meio acadêmico como na sociedade, apresentando assim sua relevância ao ser abordado. A preocupação no que diz respeito à preservação do meio ambiente é reforçada, pois corrobora com a afirmação de Souza (2011, p.43), a qual define que "os recursos do planeta são finitos e, caso não se tome providências para o controle da poluição e do aquecimento global, é possível que em longo prazo a vida na Terra se torne inviável". Pensando nessa perspectiva, muitas medidas estão sendo tomadas pelos setores públicos e até privados, para que este cenário torne-se reversível. Dentre as medidas, está à coleta seletiva, que é de vital importância para a separação do lixo nas residências e o recolhimento do mesmo pelas municipalidades, com o objetivo de aumentar a reciclagem de resíduos sólidos que teriam como destino os aterros sanitários (RODRIGUES e SANTANA, 2012).

Então, para o desenvolvimento deste trabalho, foram selecionadas três cidades que pertencem a Microrregião de Bragança Paulista no Estado de São Paulo, a critério do maior número de habitantes e maior representatividade na região, as quais são: Atibaia (138.499 habitantes), Bragança Paulista (162.435 habitantes) e Itatiba (114.912 habitantes), segundo as estimativas para 2016 do Instituto Brasileiro de Geografia e Estatística (IBGE, 2016a, 2016b, 2016c), com o intuito de obter dados sobre a coleta seletiva dessas municipalidades, que sirvam de subsídio para o desenvolvimento das atividades de Resolução de Problemas.

Tais informações serviram como conteúdo didático que, possam ser explorados no processo de ensino-aprendizagem pelos alunos do Ensino Médio por meio de atividades que englobem os conceitos de Álgebra, Aritmética, Estatística e Geometria, com a intenção de trazer a realidade o que está por trás desses conceitos e inseri-los em um cenário atualizado e de vital importância para a sociedade. A partir disto, relacionar, refletindo a respeito das dificuldades que os alunos apresentam sobre os conceitos e conteúdos matemáticos, buscando assim, uma forma alternativa de abordar o aprendizado desses, para que o ensino da Matemática torne-se mais eficaz. 


\subsection{PROBLEMA DE PESQUISA}

Estabelece-se para o trabalho, a partir do contexto e justificativa apresentados, o seguinte problema de pesquisa: "Os dados da Coleta Seletiva da Microrregião de Bragança Paulista são úteis na proposta de elaboração de atividades didáticas de Resolução de Problemas, que visem o ensino de Álgebra, Aritmética, Estatística e Geometria, para as séries do Ensino Médio?".

\subsection{HIPÓTESE}

A hipótese inicial que se estabelece para o trabalho é que os dados da coleta seletiva da Microrregião de Bragança Paulista são úteis na proposta de elaboração de atividades didáticas de Resolução de Problemas que visam o ensino de Álgebra, Aritmética, Estatística e Geometria para as séries do Ensino Médio. Além de, estimular a discussão sobre a problemática envolvida na destinação correta dos resíduos sólidos.

\subsection{OBJETIVOS}

O trabalho buscou atingir o objetivo geral e os objetivos específicos descritos nos itens 1.4.1 e 1.4.2.

\subsubsection{OBJETIVO GERAL}

O principal objetivo deste trabalho é desenvolver, na perspectiva de fornecer aos envolvidos da área de ensino e demais interessados, um modo de utilizar o Método de Resolução de Problemas (MRP) de Polya no contexto da Coleta Seletiva da Microrregião de Bragança Paulista, para servir de apoio ao ensino de conceitos matemáticos de Álgebra, Aritmética, Estatística e Geometria do Ensino Médio (EM), e que também possam fornecer uma reflexão acerca do tratamento dado aos resíduos sólidos gerados pelos municípios.

\subsubsection{OBJETIVOS ESPECÍFICOS}

Para o desenvolvimento do trabalho foram estabelecidos os seguintes objetivos específicos:

Levantar na literatura das áreas de Educação e Matemática, os referenciais teóricos para embasar as atividades didáticas desenvolvidas;

Coletar dados e informações sobre a coleta seletiva nas cidades selecionadas da Microrregião de Bragança Paulista nos municípios de Atibaia-SP, Bragança Paulista-SP e Itatiba-SP.

Realizar a triagem e análise dos dados obtidos sobre a coleta seletiva; e,

Elaborar atividades didáticas de Resolução de Problemas, baseadas nos dados coletados, que busquem estimular o aprendizado de conteúdos matemáticos, e que consequentemente tragam uma reflexão sobre o tratamento dos resíduos sólidos gerados.

\subsection{ESTRUTURA DO TRABALHO}

Este capítulo é elaborado para explicitar qual o tema abordado, os objetivos propostos, quais os motivos que justificam a adoção do tema e em que contexto este se insere, além disso, também fornece uma hipótese ao problema proposto.

O segundo capítulo, discursa sobre o sistema educacional, a Educação Matemática, a Coleta Seletiva, a interdisciplinaridade e sobre as atividades didáticas de Resolução de Problemas, na perspectiva de profissionais da área e outros pesquisadores do tema, ou de temas similares.

O terceiro capítulo trata da abordagem metodológica, expondo a caracterização da pesquisa, o método e o objeto de estudo deste trabalho. 
No quarto capítulo, após o embasamento teórico, a pesquisa de campo e a coleta de dados, estão expostas os resultados obtidos da pesquisa e sua utilização no desenvolvimento de situaçõesproblemas para o ensino de Matemática.

No último capítulo são apresentadas as conclusões, considerações finais, limitações da pesquisa e propostas de trabalhos futuros.

Por fim, são apresentadas as referências bibliográficas, os apêndices e os anexos, que complementam o desenvolvimento deste trabalho. 


\section{Capítulo 2}

\section{Fundamentação Teórica}




\section{FUNDAMENTAÇÃO TEÓRICA}

Este capítulo apresenta a revisão bibliográfica sobre as temáticas pesquisadas e expõe o que pesquisadores da área pensam a respeito do tema pesquisado. Neste, são analisados os aspectos referentes ao sistema educacional no que tange sua legalidade e funcionamento. Também serão tratados sobre as dificuldades de ensinar Matemática dentro desse sistema e quais são as possibilidades de transpor tais dificuldades. E ainda são apresentados os contextos da Coleta Seletiva e da Interdisciplinaridade.

\subsection{SISTEMA EDUCACIONAL BRASILEIRO}

O Sistema Educacional Brasileiro se desenvolveu a partir dos rumos políticos, sociais e culturais do país. Atualmente a Lei de Diretrizes e Bases (LDB) regulariza a organização do ensino e foi formulada para atender as exigências da Constituição Federal, aprovada em 05 de Outubro de 1988. Além disso, os conteúdos escolares são definidos de acordo com as Diretrizes Curriculares Nacionais (DCN).

No capítulo III, seção 1, da Constituição Federal de 1988 (BRASIL, 1988), o Artigo no 205 define que,

A educação, direito de todos e dever do Estado e da família, será promovida e incentivada com a colaboração da sociedade, visando ao pleno desenvolvimento da pessoa, seu preparo para o exercício da cidadania e sua qualificação para o trabalho.

Em 1996 com a aprovação da LDB (1996), a Educação Básica fornecida pelos gestores públicos ficou dividida em: Educação Infantil, Ensino Fundamental e Ensino Médio (EM).

De acordo com o Artigo no 22 da LDB (1996),

A educação básica tem por finalidades desenvolver o educando, assegurar-Ihe a formação comum indispensável para o exercício da cidadania e fornecer-lhe meios para progredir no trabalho e em estudos posteriores.

No entanto, segundo Costa e Momo (2009), a escola passa por uma crise que para as autoras nada mais é do que a "expressão dos embaraços que enfrenta ao prosseguir no cumprimento de seus desígnios" (COSTA e MOMO, 2009, p. 521).

Parece, para as autoras, que a escola não tem conseguido assegurar a formação adequada, muito menos cumprir com uma das principais finalidades, que é a formação do cidadão, assegurada pela LDB.

Por outro lado, de acordo com Piana (2009), acredita que por questões ideológicas, não se pensou em democratizar o ensino, já que a "educação sempre esteve a serviço de um modelo econômico de natureza concentradora de rendas e socialmente excludente" (PIANA, 2009, p. 67).

Para a autora, a escola se formou para atender a evolução das relações trabalhistas, que surgiram no contexto da era industrial e, consequentemente atender as demandas do mercado capitalista (PIANA, 2009).

Nos itens 2.1.1, 2.1.2 e 2.1.3 são apresentados aspectos formadores do Sistema Educacional e uma análise da situação atual do mesmo.

\subsubsection{LEI DE DIRETRIZES E BASES DA EDUCAÇÃO NACIONAL}

De acordo com o documento oficial, disponível no site do Ministério da Educação (MEC), a Lei de Diretrizes e Bases (LDB) ㄲo 9.394, de 20 de dezembro de 1996, decreta os princípios e os fins da educação. Dentre estes estão, "o pluralismo de ideias", "respeito à liberdade e apreço a tolerância", "valorização do profissional da educação escolar", "garantia de padrão de qualidade" e "vinculação entre a educação escolar, o trabalho e as práticas sociais".

Além disso, a LDB (1996) também decreta os direitos e os deveres à educação, a organização da educação nacional, os níveis e as modalidades de educação e ensino, os profissionais da educação e os recursos financeiros destinados a ela. 
Conforme o Artigo no 1 da LDB (1996),

A educação abrange os processos formativos que se desenvolvem na vida familiar, na convivência humana, no trabalho, nas instituições de ensino e pesquisa, nos movimentos sociais e organizações da sociedade civil e nas manifestações culturais.

Parágrafo 1. Esta Lei disciplina a educação escolar, que se desenvolve, predominantemente, por meio do ensino, em instituições próprias.

Parágrafo 2. A educação escolar deverá vincular-se ao mundo do trabalho e à prática social.

Para atender as exigências da LDB (1996), é importante analisar o currículo escolar, além da maneira em que são explicados e compreendidos os conteúdos, para assim instruir os cidadãos.

Por outro lado, na perspectiva de ensino de conteúdos e visando aqueles disponibilizados na área da Matemática, a LDB (1996) defende, no Artigo 3ํㅡ, o "pluralismo de ideias" e a "liberdade de aprender, ensinar, pesquisar e divulgar a cultura, o pensamento, a arte e o saber"; entre outros princípios. Do ponto de vista do ensino livre, visto que a Matemática exige o domínio de regras e conceitos, o professor deve ter pelo menos a liberdade de ensinar no momento que achar necessário os conteúdos destinados a cada série, conforme o andamento das turmas. Além disso, deve desenvolver nos estudantes a capacidade da crítica, fundamental para o raciocínio e desenvolvimento da ciência.

Em termos legais, tanto a Constituição Federal de 1988 (BRASIL,1988) quanto a LDB (1996), defendem uma Educação Básica para todos e de qualidade. Para isso, as instituições de ensino têm sua própria autonomia para elaborar os planos de ensino, que visem atingir esta meta. Por outro lado, o currículo deve seguir as determinações das Diretrizes Curriculares Nacionais (DCN) ou ainda podem recorrer aos Parâmetros Curriculares Nacionais (PCN).

\subsubsection{DIRETRIZES CURRICULARES NACIONAIS}

As Diretrizes Curriculares Nacionais (DCN) são normas de caráter obrigatório que servem para nortear a formação dos currículos das escolas. Esses estabelecem a base nacional comum para a estruturação e direcionamento das propostas pedagógicas da educação básica (DCN, 2013).

O Conselho Nacional de Educação (CNE) elaborou as diretrizes para atender as demandas educacionais por meio de critérios, princípios e procedimentos que organizem os currículos das instituições de ensino (DCN, 2013).

No caso do Ensino Médio, as diretrizes têm um foco em fortalecer sua capacidade tecnológica, na intenção de formar alunos capacitados a ocupar espaços em universidades e cursos técnicos e, suprir as demandas dos setores industriais que não expandem devido à escassez de profissionais (DCN, 2013).

As Diretrizes Curriculares Nacionais (DCN) sinalizam também que compete aos sistemas de ensino e às instituições a responsabilidade pela garantia de políticas de valorização dos profissionais do magistério da educação básica.

Nos últimos anos, o Ensino Médio (EM) tem ocupado destaque nas discussões do CNE, já que suas condições atuais estão longe de atender as necessidades, tanto da formação para a cidadania como para o mundo do trabalho (DCN, 2013).

De acordo com o DCN (2013, p.146), novas diretrizes para o EM são necessárias também,

Em virtude das novas exigências educacionais decorrentes da aceleração da produção de conhecimentos, da ampliação do acesso às informações, da criação de novos meios de comunicação, das alterações do mundo do trabalho, e das mudanças de interesse dos adolescentes e jovens.

Estes fatores inserem os jovens e adolescentes em diversos mundos de ideias e é sabido que o atendimento das demandas vai além da escola (DCN, 2013), ou seja, os alunos não passam o tempo todo na escola, mas o tempo que a frequentam tem que ser suficiente para formar cidadãos, portanto, é importante estabelecer um currículo escolar eficiente. 


\subsubsection{SITUAÇÃO ATUAL DO SISTEMA EDUCACIONAL BRASILEIRO}

O atual Sistema Educacional Brasileiro foi influenciado por uma série de eventos políticos e econômicos, os quais resultaram na tomada de decisões acerca de diversas mudanças ao longo do tempo, grande parte destas suprindo o interesse do mercado (PIANA, 2009).

Como resultado disto, hoje nos deparamos com milhares de estudantes com nível de conhecimento muito abaixo do que seria considerado ideal. De acordo com Piana (2009, p.57), "milhares de crianças, adolescentes e jovens, mesmo matriculados em uma escola, permanecem excluídos de uma educação participativa, democrática, conscientizadora, dialógica, autônoma e afetiva".

Para Costa e Momo (2009), esse cenário ultrapassa o interesse mercantil e está ligado aos propósitos dos rumos socioeconômicos, políticos e culturais.

Como reflexo das atuais mudanças políticas no cenário brasileiro, foi apresentado este ano, a Medida Provisória (MP) ํo 746/2016, que dentre as mudanças, estabelece o aumento da carga horária mínima anual do EM para 1400 horas. Além disso, torna facultativo o ensino de Arte e Educação Física para o EM e permite que conteúdos cursados sejam aproveitados no superior. A medida também possibilita a contratação de profissionais com "notório saber" para ministrar os conteúdos.

Para Lordêlo e Dazzani (2009, p. 7), "o Brasil de hoje ainda tem um grande desafio: uma educação que concilie, de um lado, a qualidade e excelência e, do outro, que pratique valores que contribuam para a democratização da sociedade". Este desafio continua latente e permite a reflexão sobre a MP no 746/2016 e, se esta apresenta propostas de qualidade ao ensino ou ainda, se promove valores democráticos.

Para Nacarato (2013, p.14), "passamos de uma sociedade capitalista, marcada pelo disciplinamento e para a qual a escola foi criada a partir de lógicas disciplinares, para uma sociedade globalizada, regida pela lógica do controle". Tal controle mantém, segundo a autora, a população na lógica que for confortável para a classe dominante.

Para Piana (2009, p.57-58),

Temos uma educação ainda em construção, com marcas profundas da exclusão social, econômica e cultural, de uma classe menos favorecida; uma educação sem investimentos e oportunidades a essa parcela da população e sob o domínio de organismos nacionais e internacionais que direcionam os rumos da educação brasileira para uma ação mercantilista.

Diante deste contexto, esta pesquisa sugere a necessidade de buscar métodos alternativos, diferentes dos tradicionais, para introduzir novas perspectivas, na busca de fornecer aos estudantes uma maior autonomia e autocritica sobre o sistema e o cenário ao qual ele está inserido.

\subsection{DESAFIOS E OBJETIVOS DE ENSINAR MATEMÁTICA}

A Matemática contribui para o desenvolvimento do pensamento, e pode fornecer aos estudantes a capacidade de resolver problemas, proporcionando uma visão ampla e cientifica da criatividade e outras capacidades pessoais (PCNEM, 2000).

Para Luiz e Col (2013 p. 1), "o ensino da matemática precisa ser atrativo e prazeroso, neste sentido, a ação docente se torna desafiadora".

Torna-se cada vez mais difícil despertarmos alunos, os quais vivem numa sociedade amplamente tecnológica e em constante transformação, o interesse por aulas cuja metodologia baseia-se apenas em exposição oral e têm como único recurso o quadro e o giz. Contudo, em geral, os professores não estão preparados para trabalhar nesta nova realidade (TERRADAS, 2011, p. 96).

Por isso, Oliveira e Vaz (2014, p. 138), acreditam que a transmissão do conhecimento irá partir de "situações problemas, abertas para debates que sejam interessantes e relevantes para quem estuda.". Dessa a maneira, se faz necessário que as escolas possuam "métodos e materiais didáticos apropriados incluindo laboratórios de ciência e informática e professores especializados" (OLIVEIRA e VAZ, 2014, p. 138). 
Para tanto, o educador da atualidade precisa criar o sentimento de necessidade de descobrir e investigar. Para isso, deve conhecer as questões sociais, ter uma boa preparação no campo especializado e ter uma noção do uso das tecnologias como ferramenta de ensino (OLIVEIRA e VAZ, 2014).

No entanto, Junqueira e Manrique (2015) ainda encontram, nos cursos de Licenciatura em Matemática, mesmo após as mudanças do mundo contemporâneo, fortes elementos que parecem solidificados como: a dicotomia entre teoria e prática; e a separação dos conteúdos específicos e pedagógicos.

Para Ogliari (2012, p. 5), "compreender a matemática sem uma articulação com a sociedade é insustentável", tem de haver uma aproximação dos conteúdos com a realidade.

\subsubsection{PORQUE ENSINAR E APRENDER MATEMÁTICA?}

A Matemática fornece uma finalidade prática, pois permite realizar tarefas do cotidiano. No entanto, a Matemática não deve reduzir-se a isso, "deve também contribuir para o desenvolvimento do raciocínio, da lógica, da coerência” (LUIZ e COL, 2013, p. 2).

Segundo Bertolucci (2011), a Matemática permeia nossa vida, e por isso é útil para ler e interpretar o mundo a nossa volta. O autor ressalta também que por meio dela pode-se modelar vários empreendimentos no mundo, e que ter controle sobre isto é bom para a humanidade. Por outro lado, deve ser utilizada de maneira crítica, ou seja, "que avaliemos também os riscos, custos, benefícios, entre outras coisas" (BERTOLUCCI, 2011, p. 30).

Para Luiz e Col (2013, p. 2),

A aprendizagem da Matemática consiste em criar estratégias que possibilitam ao aluno atribuir sentido e construir significado às ideias matemáticas. Desse modo, supera o ensino baseado apenas em desenvolver habilidades, como calcular ou fixar conceitos pela memorização ou listas de exercícios.

De acordo com o PCNEM (2000), além do caráter formativo e instrumental a Matemática também deve ser vista como ciência e que, com suas definições, demonstrações e encadeamentos conceituais, podem validar intuições por meio de novos conceitos construídos.

Bertolucci (2011) apresenta em seu trabalho sobre a opinião de Ole Skvsmose, acerca do ensino de Matemática, afirma que a Matemática está formatando a sociedade e que a era tecnológica influência de forma direta o comportamento da sociedade. E a principal ferramenta do desenvolvimento tecnológico é a Matemática, portanto, para o autor, é fundamental questionar-se sobre os riscos dos modelos matemáticos criados para a solução de problemas e criação de novas tecnologias (SKOVSMOSE, 1994 apud Bertolucci, 2011).

Para Ogliari (2012, p. 4), diante do mercado de trabalho, "a matemática tem peso eliminatório em concursos e vestibulares, colaborando para determinar quem é produtivo e útil na sociedade", isto resulta em uma "invisibilidade da desigualdade", privando cidadãos de direitos e reconhecimento social, pois separa em capazes ou não de exercer funções em certas profissões.

\subsubsection{DEFASAGENS DOS ALUNOS EM CONTEÚDOS MATEMÁTICOS}

Os alunos subestimam o conhecimento matemático apesar de viverem na era tecnológica que só se tornou possível graças ao desenvolvimento de teorias matemáticas. No entanto, é muito difícil fazer um aluno compreender que ela é necessária para o entendimento do mundo a nossa volta e que está fortemente ligada a formação da sociedade atual (SKOVSMOSE, 1994 apud BERTOLUCCI, 2011).

Por outro lado, os conteúdos abordados devem ser revistos e principalmente a abordagem destes, ou seja, a maneira de se ensinar deve ser repensada. 
Segundo Bertolucci (2011, p.35),

O que queremos que ocorra nas escolas? O discurso ideal gira em torno, e com certa naturalidade, de que os alunos sentados, todos organizados em suas fileiras, possam ouvir o professor, que fica de pé em frente ao quadro explicando a matéria. Ali não se espera outra coisa senão o professor com o domínio da matéria e o aluno prestando atenção e fazendo perguntas inteligentes. Para que dessa forma possa ocorrer a aprendizagem, o professor transmitindo o conhecimento pela fala enquanto o aluno assiste.

Para o autor, isto é perverso, mas é assim que a escola cumpre com o seu papel, recebe uma criança, the educa para viver socialmente e exercer uma profissão. Neste contexto entra a Matemática, uma vez que está em tudo e se faz necessário o domínio desta para o melhor desenvolvimento da sociedade.

No entanto, existe uma resistência por grande parte dos estudantes a compreensão da Matemática. Para D’Ambrósio (1989, p.15) "nossos alunos acreditam que fazer Matemática é seguir e aplicar regras".

Segundo Luiz e Col (2013, p. 2), "há uma busca para que os estudantes incorporem o raciocínio, o emprego da lógica, a análise das situações para a resolução das mais diferentes problematizações", no entanto, os alunos não têm o hábito da leitura e isto é um fator que dificulta a interpretação de textos e problemas (LUIZ e COL, 2013).

Para as autoras, deve haver uma troca entre aluno e professor, enquanto um ensina o outro deseja aprender, isto pode favorecer a compreensão e ampliação do conhecimento transmitido (LUIZ e COL, 2013).

\subsection{ATIVIDADES DIDÁTICAS DE RESOLUÇÃO DE PROBLEMAS}

Para Polya (1995), um dos maiores desafios do professor é auxiliar os alunos o suficiente para que adquiram experiência no trabalho independente. Para isto, o método consiste em resolver problemas por meio de quatro etapas, das quais os alunos têm maior autonomia e o professor deve apenas orientar.

O aluno deve ser independente, mas não pode ficar largado, no entanto, nem o professor deve fazer tudo. Tem de haver um meio termo, onde exista uma parcela razoável de trabalho a ser realizado pelo aluno. Isto deve ser a ação docente, para tornar os alunos independentes (POLYA, 1995).

As etapas do método, segundo Polya (1995) são:

- $\quad 1^{a}$ etapa - Compreensão do problema: o problema deve ficar bem entendido, o aluno deve ter condições de identificar as incógnitas, os dados, as condicionantes. Além disso, o problema deve ser bem escolhido para que o aluno deseje resolvê-lo. Nem muito fácil, nem muito difícil, natural e interessante;

- $\quad 2^{2}$ etapa - Estabelecer um plano: para elaborar um plano devemos conhecer quais meios podemos utilizar para chegar à resposta. "O caminho que vai desde a compreensão do problema até o estabelecimento de um plano pode ser longo e tortuoso" (POLYA, 1995, p. 5), no entanto é necessário para o desenvolvimento da independência. Além disso, fica mais fácil traçar um bom plano com conhecimento prévio do assunto e concentração no objetivo;

- $\quad 3^{a}$ etapa - Execução do plano: nesta etapa é importante verificar cada passo, para que não se ocultem erros. Também é necessária muita concentração para seguir o roteiro do plano; e,

- $\quad 4^{a}$ etapa - Retrospecto: ao se fazer um retrospecto da resolução completa, reconsiderando e reexaminando o resultado final e o caminho até este, isto pode consolidar o conhecimento e aperfeiçoar a capacidade de resolver problemas.

Como o método possibilita ao aluno autonomia sobre a solução do problema, isto gera confiança em suas habilidades matemáticas. É diferente propor que alcance um conceito sem antes nunca ter tido qualquer contato com o conteúdo. O caminho é muito mais longo e tortuoso, no entanto gera identificações (POLYA, 1995). 
Resolver problemas "entusiasma a busca de soluções, o que resulta na produção de conhecimento" (LUIZ e COL, 2013, p. 7).

A Resolução de Problemas tem uma diferença muito sutil em relação à resolução de exercícios, e por isso difícil determinar cada uma, então é necessário buscar atividades em que ocorra um pensamento reflexivo com maior significado, em detrimento, de uma resolução mecânica (CLEMENT e TERRAZAN, 2011).

Porém, para D’Ambrósio (1989), também devem ser exploradas situações que criem curiosidade e motivem o aluno a solucionar os problemas. Neste trabalho são criadas situações-problema baseadas no contexto da Coleta Seletiva para motivar o ensino-aprendizagem dos alunos no que tange os conteúdos de matemática.

\subsection{COLETA SELETIVA}

Devido ao crescente desenvolvimento industrial houve um agravamento do problema de produção e descarte de lixo, pois o que antes era em grande parte orgânico, hoje em grande parte são resíduos sólidos, como: plástico, borracha, papel, entre outros, que demoram a se decompor e vão se acumulando ao longo do tempo. Pensando em soluções para este problema, foi criado o sistema de Coleta Seletiva dos resíduos sólidos (SOUZA, PAULA e SOUZA-PINTO, 2012).

Para Souza et al. (2013, p.85), "a coleta seletiva é uma alternativa ecologicamente correta que desvia do destino em aterros sanitários ou lixões, resíduos sólidos que podem ser reciclados". Para os autores, a Coleta Seletiva contribui para o desenvolvimento sustentável.

Segundo Jacobi e Besen (2011), a disposição dos resíduos sólidos vem sendo uma preocupação em escala global desde a conferência Rio $92{ }^{1}$, por isso, medidas que maximizem o reaproveitamento, como a coleta seletiva e a reciclagem, são prioridades.

De acordo com Garofolo et al. (2011, p. 2), "A temática de como dispor os resíduos sólidos tem tomado corpo nas discussões sociais, sendo este um dos principais problemas a ser resolvido, principalmente nos grandes centros urbanos".

A produção de resíduos sólidos cresce na medida do crescimento populacional e da concentração urbana. Além disso, modelos de desenvolvimento como a obsolescência programada, a descartabilidade de produtos e o consumo exagerado de supérfluos, contribuem para o agravamento da situação, deixando evidente que os padrões de consumo devem se tornar sustentáveis e os resíduos sólidos produzidos, devem ser gerenciados adequadamente (JACOBI e BESEN, 2011).

No entanto, "há uma série de circunstâncias que dificultam a implantação e a manutenção da coleta seletiva e que precisam ser confrontados com os benefícios que esse sistema pode gerar" (RODRIGUES e SANTANA, 2012, p. 300).

Para Souza et al. (2013, p.85), "a coleta seletiva deve ser vista como uma corrente de três elos: Destinação, Logística e Educação Ambiental”.

De acordo com Bringhenti e Günther (2011, p. 422),

A comunidade deve ser sensibilizada, motivada e os conceitos e práticas precisam ser assimilados e incorporados no cotidiano da população envolvida, com vistas a assegurar sua operacionalização, viabilidade e continuidade, fatores fundamentais para se atingir os resultados esperados e garantir sua sustentabilidade.

Souza et al. (2013), sugere que os saberes ambientais sejam trabalhados pelo meio educacional, uma vez que estes formam a base da sociedade, para que conceitos como Coleta Seletiva sejam disseminados para educar a população. O autor ainda recomenda que sejam conceitos trabalhados de forma interdisciplinar, ou seja, é necessário relacionar, como no caso da pesquisa, conteúdos

\footnotetext{
${ }^{1}$ Foi a Conferência das Nações Unidas sobre o Meio Ambiente e o Desenvolvimento, realizada no Rio de Janeiro, em junho de 1992. Também conhecida como Cúpula da Terra, ela reuniu mais de 100 chefes de Estado para debater formas de desenvolvimento sustentável, um conceito relativamente novo à época.
} 
matemáticos com a Coleta Seletiva, por exemplo, para incorporar os saberes ambientais a sociedade.

\subsubsection{LEI FEDERAL № 12.305/2010}

$\mathrm{Na}$ busca de cumprir exigências mundiais e nacionais a Lei Federal 끄 12.305 foi sancionada em 2 de agosto de 2010 e trata da regulamentação dos resíduos sólidos e de acordo com o Artigo nํㅜ 1,

Institui a Política Nacional de Resíduos Sólidos, dispondo sobre seus princípios, objetivos e instrumentos, bem como sobre as diretrizes relativas à gestão integrada e ao gerenciamento de resíduos sólidos, incluída os perigosos, às responsabilidades dos geradores e do poder público e aos instrumentos econômicos aplicáveis.

Para Oliveira e Junior (2016), a aprovação da Lei no 11.445/2007(Lei Nacional de Saneamento Básico- LNSB) e da Lei no 12.305/2010 (Política Nacional de Resíduos Sólidos - PNRS), é um marco regulatório. Pois, essa exige que nos Planos Municipais de Saneamento Básico (PMSB), devem conter metas para o manejo de resíduos sólidos, entre outras coisas. E esta, estabelece: diretrizes gerais aplicáveis aos resíduos sólidos; o fim dos lixões; e a criação dos Planos de Gestão Integrada de Resíduos Sólidos (PGIRS); entre outros (OLIVEIRA e JUNIOR, 2016, p. 55-56).

O Artigo $n^{\circ} 3$ define nos incisos V, VII e XIV o significado para:

$\mathrm{V}$ - coleta seletiva: coleta de resíduos sólidos previamente segregados conforme sua constituição ou composição;

VII - destinação final ambientalmente adequada: destinação de resíduos que inclui a reutilização, a reciclagem, a compostagem, a recuperação e o aproveitamento energético ou outras destinações admitidas pelos órgãos competentes do SISNAMA (Sistema Nacional de Meio Ambiente), do SNVS (Sistema Nacional de Vigilância Sanitária) e do SUASA (Sistema Unificado de Atenção à Sanidade Agropecuária), entre elas a disposição final, observando normas operacionais específicas de modo a evitar danos ou riscos à saúde pública e à segurança e a minimizar os impactos ambientais adversos;

XIV - reciclagem: processo de transformação dos resíduos sólidos que envolve a alteração de suas propriedades físicas, físico-químicas ou biológicas, com vistas à transformação em insumos ou novos produtos, observadas as condições e os padrões estabelecidos pelos órgãos competentes do Sisnama e, se couber, do SNVS e do SUASA.

O PNRS reconhece no inciso VIII do Artigo nำ 6, o resíduo sólido reutilizável e reciclável como um bem econômico e de valor social, gerador de trabalho e renda e promotor de cidadania. Enquanto o inciso X determina "o direito da sociedade à informação e ao controle social".

De acordo com Oliveira e Junior (2016, p. 57)

O controle social é necessário em regimes democráticos, visando à proteção ao interesse público. 0 processo de construção dos planos deve ser transparente e participativo. O plano torna-se mais efetivo com a apropriação pela sociedade, que passa a enxergar-se nas ações planejadas, além de permitir seu acompanhamento.

Os autores ressaltam que, para atingir as obrigações da lei tem de haver um planejamento que contenha estratégias, metas e ações, que só é possível com o conhecimento da situação atual dos resíduos sólidos (OLIVEIRA e JUNIOR, 2016).

\subsubsection{PLANO MUNICIPAL DE SANEAMENTO BÁSICO E PLANO DE GESTÃO INTEGRADA DE RESÍ́DUOS SÓLIDOS}

O Plano Municipal de Saneamento Básico (PMSB) é o instrumento de planejamento da prestação dos serviços de saneamento básico municipal (B\&B ENGENHARIA, 2015).

O PMSB consolida os estudos técnicos de engenharia, jurídicos, econômicos e financeiros, necessários à análise de viabilidade e estruturação da política municipal de limpeza urbana e 
manejo de resíduos sólidos. Foi desenvolvido em conformidade com a Lei Federal ํํ 11.445/2007, que estabelece a política Nacional de Saneamento Básico (LNSB) e, também, com a Lei Federal no 12.305/2010, que estabelece a Política Nacional de Resíduos Sólidos (PNRS), especificamente no tocante aos serviços públicos de limpeza urbana e manejo de resíduos sólidos (BRASIL, 2010).

Em conformidade com a Lei Federal no 11.445/2007 (BRASIL, 2007), a definição de saneamento básico foi além do conceito tradicional, que alcançava somente os serviços de abastecimento de água potável e esgotamento sanitário. A nova concepção inclui também a drenagem e manejo de águas pluviais e a limpeza urbana e manejo de resíduos sólidos.

Na sua concepção, o documento foi estruturado de forma a apresentar o diagnóstico das atividades relacionadas com a limpeza urbana, descrevendo a caracterização dos serviços existentes, focando a situação atual da coleta de resíduos sólidos domésticos, coleta seletiva de materiais recicláveis, limpeza e conservação urbana, resíduos de serviços de saúde, resíduos da construção civil, resíduos especiais e industriais detalhando o funcionamento desses serviços e suas especificidades (B\&B ENGENHARIA, 2015).

Segundo o Artigo 19 da PNRS (BRASIL, 2010), no PGIRS contém, o diagnóstico das situações de resíduos sólidos gerados, desde a implantação de possíveis soluções para o seu manuseio, passando pela implementação de regras para o transporte, treinamento técnico, programas de educação ambiental, á controle e fiscalização. O parágrafo 1 deste artigo define que o PGIRS pode estar inserido no PMSB, "desde que respeitado o conteúdo mínimo previsto no mesmo artigo, ou seja, ter a abrangência estendida para além dos resíduos sólidos urbanos" (OLIVEIRA e JUNIOR, 2016, p. 57).

\subsection{INTERDISCIPLINARIDADE: MATEMÁTICA E COLETA SELETIVA}

A interdisciplinaridade no âmbito escolar pretende utilizar os conhecimentos de várias disciplinas para resolver um problema ou compreender um determinado fenômeno sob diferentes pontos de vista. Assim, o mundo a nossa volta torna-se mais compreensível e menos fragmentado. "A interdisciplinaridade tem uma função instrumental. Trata-se de recorrer a um saber diretamente útil e utilizável para resolver às questões e aos problemas sociais contemporâneos" (PCNEM, 2002, p. 34).

A palavra interdisciplinaridade é formada por três termos: inter - que significa ação recíproca, ação de $\mathrm{A}$ sobre $\mathrm{B}$ e de $\mathrm{B}$ sobre $\mathrm{A}$; disciplinar - termo que diz respeito à disciplina, do latim discere aprender, discipulus - aquele que aprende e o termo dade - corresponde à qualidade, estado ou resultado da ação (AUIB, 2006 apud TERRADAS, 2011, p. 97).

Segundo Bonatto et al. (2012, p. 2), "a interdisciplinaridade não se trata de eliminar as disciplinas, trata-se de torná-las comunicativas entre si, concebê-las como processos históricos e culturais".

Para Fernandes (2010, p. 25),

O ensino da matemática contextualizada encontra no tema "Meio Ambiente" um terreno fértil para seu pleno desenvolvimento. Diferentes conceitos matemáticos são necessários para a explicitação e o entendimento das questões ambientais emergentes.

"A inclusão da interdisciplinaridade nas aulas de Matemática é uma maneira de se tratar os temas sociais que estão em evidência e que estão presentes no dia a dia de nossa sociedade" (DUARTE, 2011, p. 378).

De acordo com Oliveira e Junior (2016, p. 55), as soluções para os problemas socioambientais devem considerar uma "complexa interdisciplinaridade" entre os campos da ciência e do conhecimento.

Segundo Duarte (2011, p. 374),

Contribuindo para a formação de cidadãos conscientes, tendo em vista esse tema transversal, a disciplina de matemática pode contribuir através de ferramentas que quantifiquem os aspectos envolvidos em problemas ambientais, possibilitando fazer intervenções necessárias.

"Mais do que se limitar a uma educação relacionada somente ao meio ambiente, a educação para a sustentabilidade está ligada a interdisciplinaridade, de relacionar o social ao meio ambiente, sem 
descartar o econômico, visando à sustentabilidade e o bem-estar da sociedade" (SOUZA et al., 2013, p. 86).

\subsection{BREVE RESUMO DO CAPÍTULO}

Este capítulo apresenta o embasamento teórico sobre Educação, Educação Matemática e Coleta Seletiva. Verificou-se que, para transpor as dificuldades de ensino, as quais o sistema educacional enfrenta, é necessário inserir dispositivos educacionais eficazes como o MRP para superá-las. Além disso, por conta dos problemas ambientais é necessário integrar os conhecimentos ambientais, como a coleta seletiva, ao meio educacional, já que este educa a sociedade. 
Capítulo 3

Método 


\section{MÉTODO}

Este capítulo apresenta o método utilizado para trazer resposta ao problema proposto. Segundo Marconi e Lakatos (2010, p. 218), "os trabalhos científicos devem ser elaborados de acordo com normas preestabelecidas e com os fins que a destinam", por isto, foi estabelecido e organizado em: caracterização da pesquisa, método e objeto de estudo. Para assim atingir os objetivos da pesquisa.

\subsection{CARACTERIZAÇÃO DA PESQUISA}

A caracterização da pesquisa desenvolvida neste trabalho é de natureza aplicada, pois segundo Gil (2017), se estrutura no contexto da busca por inovações de educar, no caso da pesquisa, um modo de utilizar o Método de Resolução de Problemas no contexto da coleta seletiva com a finalidade de ensinar Matemática para o Ensino Médio.

Este trabalho apresenta, quanto ao método, abordagem qualitativa, pois segundo Silva e Menezes (2005, p. 20), "o ambiente natural é a fonte direta para coleta de dados e o pesquisador é o instrumento-chave", ou seja, os dados precisaram ser coletados e pensados de que maneira seriam úteis nos problemas criados.

Para Silva e Menezes (2005), uma das consequências da pesquisa qualitativa é ter objetivo descritivo, que é observar, registrar e analisar os fenômenos. Além disso, essa também possui objetivo explicativo, pois, visa identificar os fatores que determinam ou contribuem para a ocorrência dos fenômenos (SILVA e MENEZES, 2005), ou seja, os objetivos metodológicos pretendem determinar como os dados extraídos se tornaram situações-problemas.

O procedimento técnico deste trabalho envolve a pesquisa bibliográfica, que acordo com Gil (2017), toda pesquisa pressupõe um embasamento teórico, no caso do trabalho foram pesquisados autores do seguimento de Educação, Educação Matemática e Coleta Seletiva, para fundamentar a pesquisa. Além disso, foi utilizado o procedimento de análise documental, que corroborando com Gil (2017), se desenvolve a partir de documentos que não receberam o tratamento analítico. No caso da pesquisa, foram analisados os PMSBs e PMGIRSs de Bragança Paulista-SP e Itatiba-SP e o PMCS de Atibaia-SP. A Figura 3.1 apresenta as características deste trabalho.

Figura 3.1. Característica da pesquisa.

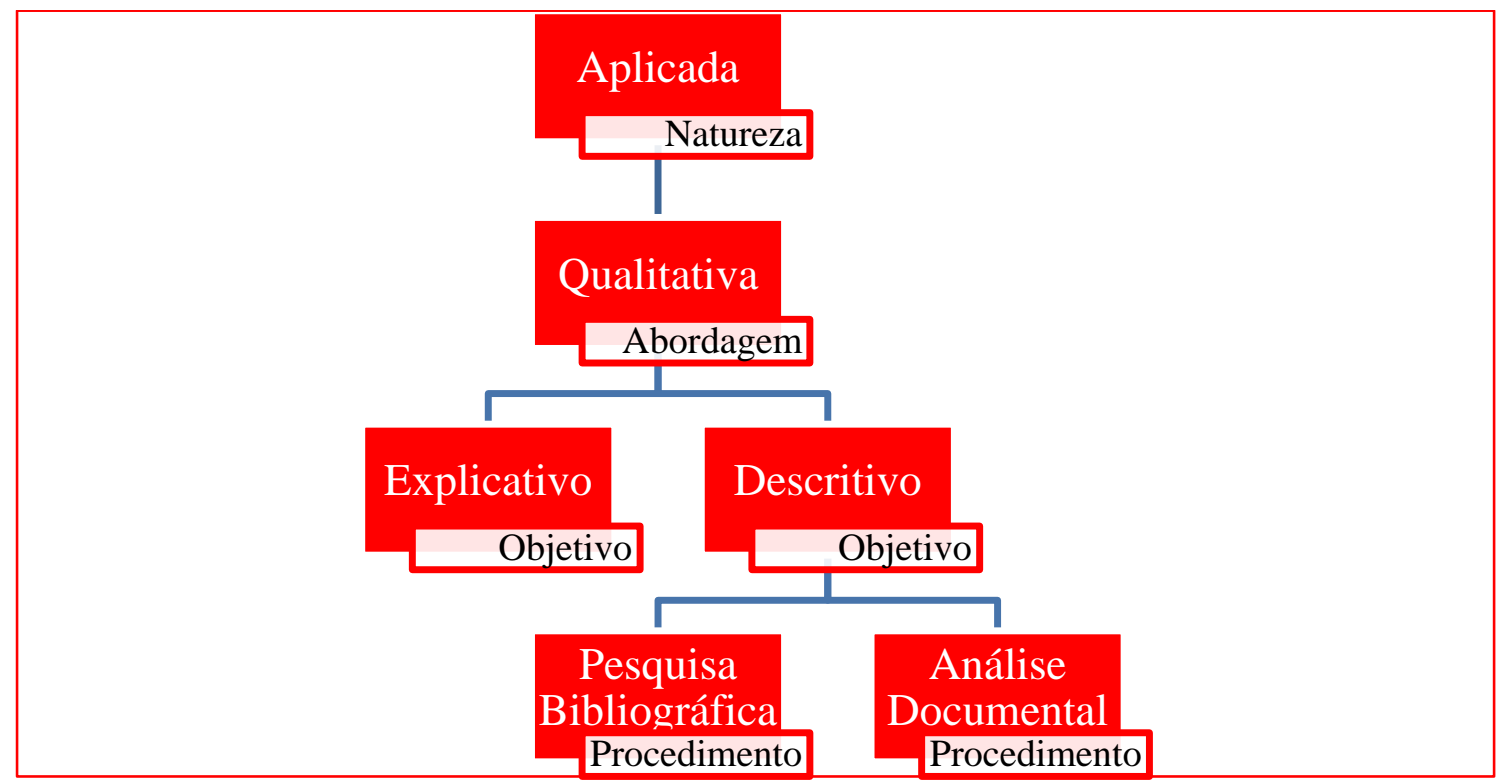

Fonte: Elaborado pelo autor. 
Neste trabalho, as informações e dados referentes à coleta seletiva foram extraídos dos Planos Municipais de Saneamento Básico (PMSBs) e dos Planos de Gestão Integrado de Resíduos Sólidos (PGIRSs) dos municípios pesquisados.

\subsection{MÉTODO}

Para reunir informações referentes à Coleta Seletiva dos municípios de Atibaia-SP, Bragança Paulista-SP e Itatiba-SP, utilizou-se consulta em documentos disponíveis nos sites das prefeituras e das empresas responsáveis pela prestação de serviço da coleta seletiva.

Os documentos consultados são: o Plano Municipal de Coleta Seletiva de Atibaia-SP; o Plano Municipal de Saneamento Básico e Plano Municipal de Gestão Integrada de Resíduos Sólidos de Bragança Paulista-SP e o Plano Municipal de Saneamento Básico e Plano Municipal de Gestão Integrada de Resíduos Sólidos de Itatiba-SP.

O PMSB e PMGIRS são documentos, como o citado no item 2.4.2, que devem apresentar os diagnósticos e prognósticos referentes ao saneamento básico e tratamento dado aos resíduos sólidos gerados.

O Plano Municipal de Coleta Seletiva de Atibaia-SP é um documento estritamente voltado a Coleta Seletiva (PMCS). Por isto foi totalmente analisado.

Por outro lado, do PMSB e PMGIRS de Bragança Paulista-SP, só foi analisado, do Volume I, o item 13.7 (Coleta Seletiva e Reciclagem) do capítulo V (Limpeza Urbana e Manejo de Resíduos Sólidos Caracterização e Diagnóstico);

E do PMSB e PMGIRS de Itatiba-SP, somente foram extraídas informações do item 26.3.2.2 (Resíduos sólidos domiciliares recicláveis) do capítulo VI (Diagnóstico de Sistema de Manejo e Disposição Final dos Resíduos Sólidos).

As informações extraídas foram dados quantitativos e qualitativos, tais como dados estatísticos, quantidades e porcentagens dos materiais reciclados ou ainda os cronogramas de coleta, enfim, qualquer informação que explore o processo de reciclagem de uma maneira geral. As informações procuradas deveriam ser úteis para criar situações-problemas que envolvessem conceitos e conteúdos matemáticos.

Inicialmente, as informações foram avaliadas e agrupadas para decidir quais conteúdo e/ou conceitos matemáticos poderiam ser trabalhados. No Quadro 3.1, é apresentado um esquema de agrupamento entre os dados coletados e os conteúdos abordados.

Quadro 3.1 Agrupamento de informações da coleta seletiva.

\begin{tabular}{|c|c|}
\hline Dados coletados & Conteúdos abordados \\
\hline Informações numéricas de materiais coletados & Aritmética e Álgebra \\
\hline Dimensão dos espaços e maquinários & Geometria \\
\hline Tabelas e gráficos & Estatística \\
\hline
\end{tabular}

Fonte: Elaborado pelo autor.

Após determinar os conteúdos e/ou conceitos matemáticos, foi iniciado um processo criativo, que consistia em direcionar a informação para o conteúdo e/ou conceito. Para construir atividades coesas e fieis a realidade foi necessário compreender o processo da coleta seletiva, e assim evitar exageros ou equívocos na contextualização de situações-problema, o que permite explicar aos alunos como funciona o processo de reciclagem. Segundo Santos e Fleith (2015, p.756), "um produto ou resultado será considerado criativo se for novo, útil e a tarefa possibilitar múltiplas respostas". A criatividade foi útil para imaginar as atividades utilizando as informações coletadas e integrá-las com os conteúdos e/ou conceitos matemáticos que foram trabalhados. 
No desenvolvimento da Atividade 1 e 2 (itens 4.2.1 e 4.2.2), primeiramente foi criada a situaçãoproblema, em seguida, como os dados dos documentos eram insuficientes, foi preciso obter informações com maior aderência. Por isso, foi encaminhado um e-mail à cooperativa "Recicle Bragança". Neste, constava um questionário, conforme apresentado no Apêndice A, com cinco perguntas, sobre as medidas das dimensões do contêiner e do fardo, quantos fardos cabem em um contêiner, peso que o contêiner suporta e quanto pesa um fardo de cada material triado.

A Figura 3.2 apresenta os elementos que foram necessários para a construção das atividades didáticas. O primeiro elemento foi reunir as informações sobre a Coleta Seletiva. O segundo elemento foi definir que conteúdos e conceitos poderiam ser trabalhados com as informações e o último elemento foi responsável por integrar os dois primeiros elementos em uma situação-problema, envolvendo as informações obtidas (primeiro elemento) com os conceitos que poderiam ser trabalhados (segundo elemento).

Figura 3.2 Processo de criação da atividade didática.

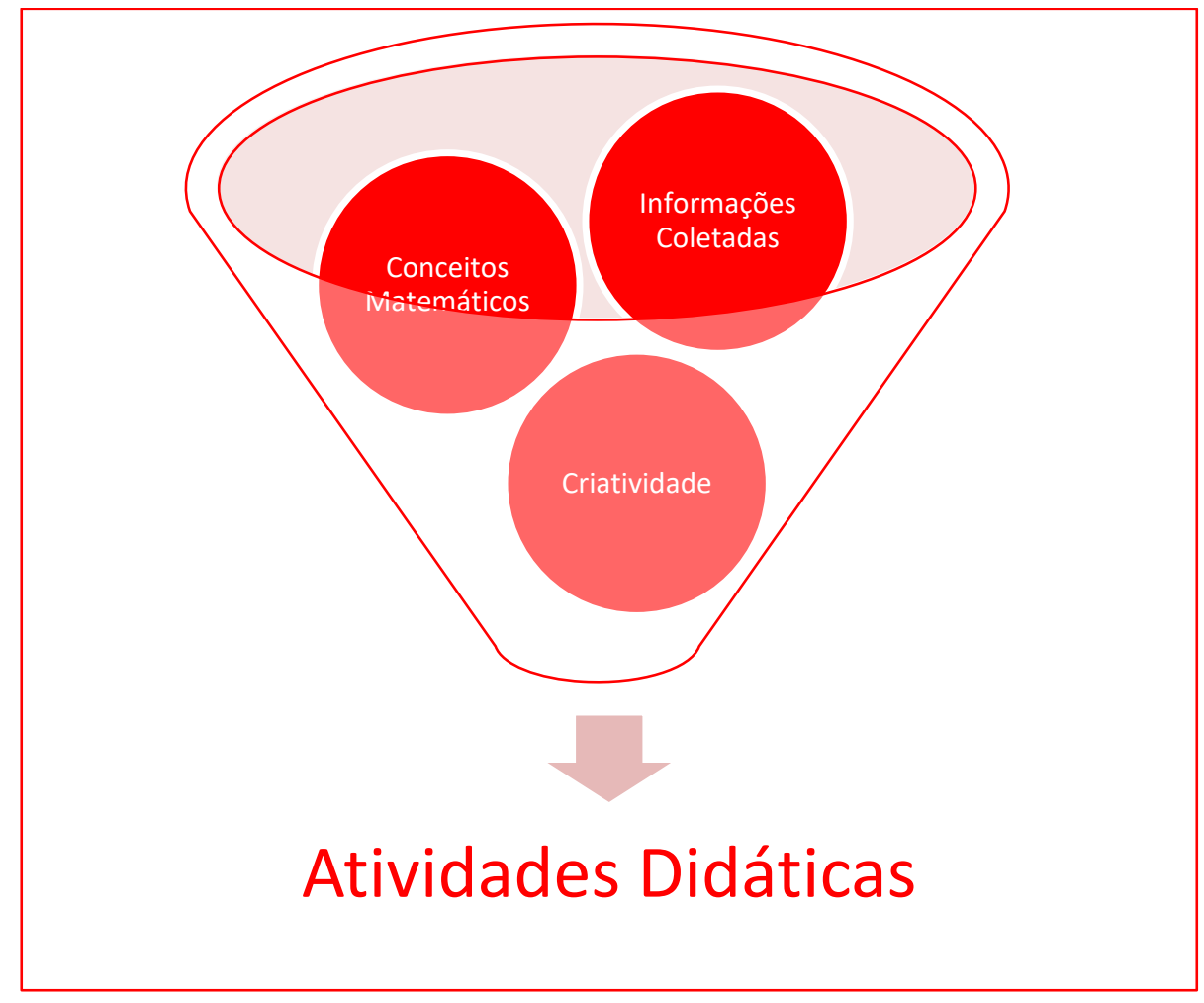

Fonte: Elaborado pelo autor.

Por fim, depois de delineadas as atividades, o MRP foi utilizado para encontrar as soluções dos problemas propostos.

É necessário destacar que para a elaboração de atividades didáticas por meio do Método de Resolução de Problemas (MRP), neste trabalho, foram utilizadas as bibliografias:

a) IEZZI, Gelson, DOLCE, Oswaldo e MACHADO, Antonio. Matemática e Realidade. 7. ed. São Paulo: Atual, 2014;

b) IEZZI, Gelson; MURAKAMI, Carlos. Fundamentos de Matemática Elementar. v. 1. 8. ed.. São Paulo: Atual, 2013;

c) IEZZI, Gelson; DOLCE, Oswaldo; MACHADO, Antonio. Matemática: volume único. 5. ed. São Paulo: Saraiva, 2011;

d) IEZZI, Gelson; HAZZAN, Samuel; DEGENSZAJN, David. Fundamentos de Matemática Elementar. vol. 11. São Paulo: Atual, 2013; 
e) IEZZI, Gelson; DOLCE, Oswaldo; DEGENSZAJN, David; PÉRIGO, Roberto; ALMEIDA, Nilze de. Matemática: ciência e aplicações. v. 1. São Paulo: Atual, 2013.

\subsection{OBJETO DE ESTUDO E PROCESSO DE DESENVOLVIMENTO}

Para encontrar soluções para os problemas propostos das atividades criadas, foi necessário utilizar o MRP. As quatro etapas do método, solucionaram todos os problemas criados e trouxeram à luz debates sobre os conceitos matemáticos envolvidos e ainda sobre questões do processo da Coleta Seletiva.

Segundo Polya (1995, p. 3),

Ao procurarmos a solução, podemos variar continuamente o nosso ponto de vista, a nossa maneira de encarar o problema. Temos de mudar de posição de quando em quando. É provável que a nossa concepção do problema seja muito incompleta no princípio; a nossa perspectiva é outra depois de feito algum progresso; ela é ainda mais diferente quando estamos quase a chegar à solução.

Para explicar a utilização do MRP de Polya (1995), criou-se o Exemplo 1: Os dados triados e reciclados em 2014 do município de Itatiba-SP, estão representados no Quadro 3.2. O administrador da cooperativa "Reviver" deseja encontrar as porcentagens de cada material representado neste quadro.

Quadro 3.2 Material triado e reciclado no município de Itatiba-SP em 2014.

\begin{tabular}{|c|c|}
\hline Material & Quantidade (ton.) \\
\hline Papel e papelão & 500 \\
\hline Plástico & 170 \\
\hline Metais & 80 \\
\hline Vidros & 170 \\
\hline Alumínio & 10 \\
\hline Outros & 70 \\
\hline Total & 1.000 \\
\hline
\end{tabular}

Fonte: Adaptado de N S Engenharia (2016).

A primeira etapa do método consiste em compreender o problema, e isso depende do nível de conhecimento que se possui sobre o tema do problema, pode ser muito ou pouco. Essa etapa é importante pois relaciona os conteúdos. Neste cabe perguntar aos alunos, "Qual a incógnita?", "O que se pede?", "Quais os dados?". O importante é que, a compreensão da incógnita ou do que se procura fique bem clara. No caso, pretende-se construir um gráfico com as porcentagens de: papel e papelão, plástico, metais, vidros, alumínio e outros. Para isto, estão disponíveis as informações referentes à quantidade, em toneladas, de cada um dos materiais citados, ou seja, possui-se mais de uma incógnita.

A segunda etapa consiste em fazer um plano para encontrar a solução. Isso também vai depender dos conhecimentos que o aluno possui, uma vez que, quanto mais forem limitados os seus conceitos matemáticos, os caminhos a se percorrer podem ser longos. Essa é uma fase que depende muito do que se compreendeu na primeira etapa e da limitação dos conhecimentos que já foram obtidos. Nesta, cabe perguntar, "já realizou um problema similar?", "como podemos nomear as incógnitas?". Devemos induzir o aluno a pensar em uma solução. Neste caso, o mais comum, é descobrir cada uma das incógnitas utilizando regra de três simples.

A terceira etapa equivale a colocar o plano em ação, nesta ocorre de maneira prática tudo o que foi previamente planejado. Seguir os passos do planejamento envolve colocar a prova o conhecimento. Se de fato, não conhece os conceitos, toda a compreensão e planejamento do problema é em vão. 
Para prosseguir na resolução do problema, calculou-se a porcentagem de cada um dos materiais da seguinte maneira:

$$
\begin{aligned}
1000 \text { ton } & \rightarrow 100 \% \\
500 \text { ton } & \rightarrow x \%
\end{aligned}
$$

Realizado o cálculo da regra de três:

$$
\begin{gathered}
x=\frac{500 \times 100}{1000} \\
x=50 \%
\end{gathered}
$$

Analogamente para os demais materiais obtêm-se as demais porcentagens. Para organizar colocouse no Tabela 3.1 uma nova coluna para as porcentagens obtidas.

Tabela 3.1 Quantidade e porcentagem dos materiais triados no município de Itatiba em 2014.

\begin{tabular}{|c|c|c|}
\hline Material & Quantidade (ton.) & Porcentagem (\%) \\
\hline Papel e papelão & 500 & 50 \\
\hline Plástico & 170 & 17 \\
\hline Metais & 80 & 17 \\
\hline Vidros & 170 & 1 \\
\hline Alumínio & 10 & 7 \\
\hline Outros & 70 & 100 \\
\hline Total & 1.000 & \\
\hline
\end{tabular}

A quarta etapa corresponde ao retrospecto, é uma etapa que consiste em verificar se o resultado é o que estava-se procurando. Além disso, nesta etapa deve-se analisar os passos e verificar se não foram cometidos erros e os encadeamentos lógicos que foram estabelecidos. Isto serve, também, para consolidar o conhecimento e com essa prática é possível "aperfeiçoar a sua capacidade de resolver problemas" (POLYA, 1995, p. 10). É necessário fazer o aluno perceber que pode utilizar os resultados a outros problemas. Perguntas como, "Podemos utilizar o resultado em outro problema?" e "É possível verificar o resultado?", são úteis nesta fase.

"O professor que deseja desenvolver nos estudantes a capacidade de resolver problemas deve incutir em suas mentes algum interesse por problemas e proporcionar-Ihes muitas oportunidades de imitar e de praticar" (POLYA, 1995).

Como verificado no Exemplo 1, o MRP permite apresentar um panorama geral do problema e da solução, ou seja, após utilizar o método é possível observar o encadeamento lógico que trouxe resposta ao problema. Com isto, é possível relacionar com outros problemas similares, ou ainda servir para problemas de maior dificuldade. Para cada uma das atividades de resolução de problemas, o professor responsável pelo conteúdo, poderá elaborar um plano de aula com o objetivo de nortear a aplicação da atividade. Uma proposta de plano de aula do Exemplo 1 é apresentado no Apêndice B, a qual poderá ser base para as outras atividades. 


\subsection{BREVE RESUMO DO CAPÍTULO}

Neste capítulo, inicialmente foram apresentadas as classificações e os procedimentos metodológicos. Também foi mostrado de que maneira foram desenvolvidas as atividades de Resolução de Problemas. Por último, foi utilizado o MRP para solucionar o Exemplo 1, explicando como utilizar cada uma das etapas do método. 


\section{Capítulo 4}

Análise de Dados 


\section{ANÁLISE DE DADOS}

Neste capítulo, será feita a apresentação dos dados extraídos dos documentos municipais. Em seguida, serão apresentadas as atividades de Resolução de Problemas, que foram criadas a partir desses dados.

\subsection{DADOS RELATIVOS A COLETA SELETIVA DA MICRORREGIÃO DE BRAGANÇA PAULISTA}

Nos municípios da Microrregião de Bragança Paulista, as empresas contratadas pelos gestores municipais realizam a coleta seletiva de porta em porta e encaminham o material coletado para as cooperativas locais. O material coletado é triado e vendido. A verba arrecadada é utilizada para a manutenção das cooperativas. Os dados coletados dos municípios de Atibaia, Bragança Paulista e Itatiba, são apresentados respectivamente, nos itens 4.1.1, 4.1.2 e 4.1.3.

\subsection{PLANO MUNICIPAL DE COLETA SELETIVA DE ATIBAIA-SP}

Atibaia insere-se na Microrregião de Bragança Paulista. Conforme a projeção para 2016, o município possui 138.499 habitantes, uma área de $478,5821 \mathrm{~km}^{2}$ e densidade demográfica de $264,57 \mathrm{hab} / \mathrm{km}^{2}$ (IBGE, 2016a).

As informações referentes a coleta seletiva foram extraídas do Plano Municipal de Coleta Seletiva de Atibaia (FELCO FALEIROS, 2015).

A área da Central de Triagem e Transbordo foi concedida pela Prefeitura e a empresa pública Saneamento Ambiental Atibaia (SAAE), esta que disponibiliza à "Cooperativa São José", apoio técnico/operacional, custeio com energia elétrica, manutenção das instalações (balança, esteira, limpeza), entre outros.

De acordo com o Felco Faleiros (2015), a coleta seletiva é realizada na área central do município semanalmente sendo que a rotina de coleta atende 69 bairros.

A cooperativa já chegou a reciclar 11 a 12\% dos resíduos domiciliares por dia. No entanto, em 2013 o percentual de reciclagem passou para a média diária de $8,2 \%$, pois os resíduos vêm misturados, então os cooperados escolhem na esteira apenas o que possui maior valor agregado, já que a esteira opera na velocidade alta. O Quadro 4.1 apresenta a quantidade de resíduos reciclados, em toneladas, durante 2012 e 2013.

Quadro 4.1 Quantidade de resíduos reciclados, em toneladas, em 2012 e 2013.

\begin{tabular}{|c|c|c|}
\hline \multirow{2}{*}{ Período } & \multicolumn{2}{|c|}{ Resíduos reciclados (toneladas) } \\
\cline { 2 - 3 } & 2012 & 2013 \\
\hline Janeiro & 327,97 & 299,34 \\
\hline Fevereiro & 245,30 & 198,83 \\
\hline Março & 310,51 & 225,84 \\
\hline Abril & 313,67 & 209,92 \\
\hline Maio & 297,14 & 253,93 \\
\hline Junho & 331,69 & 262,54 \\
\hline Julho & 249,55 & 251,43 \\
\hline Agosto & 300,82 & 256,93 \\
\hline Setembro & 207,06 & 165,41 \\
\hline Outubro & 351,69 & 289,15 \\
\hline Novembro & 235,04 & 260,07 \\
\hline Dezembro & 224,45 & 279,47 \\
\hline Total anual & 3394,89 & 2952,86 \\
\hline Média mensal & 282,91 & 246,07 \\
\hline Média diária & 9,43 & 8,20 \\
\hline
\end{tabular}

Fonte: Felco Faleiros (2015). 
De acordo com o Quadro 4.2, a central de triagem e transbordo reciclou, em 2013, 7,34\% do que foi coletado, o Quadro 4.2 também apresenta as informações referentes aos materiais reciclados durante 2013.

Quadro 4.2 Produção, em toneladas, referente a 2013 de reciclados por tipo de produto.

\begin{tabular}{|c|c|c|c|c|c|c|c|c|c|}
\hline $\begin{array}{l}\text { Período } \\
\text { mês/ano }\end{array}$ & Papel & Sucata & Alumínio & Plástico & PET & Vidro & $\begin{array}{l}\text { Tetra } \\
\text { Pak }\end{array}$ & $\begin{array}{c}\text { Reciclado } \\
\text { (ton.) }\end{array}$ & $\begin{array}{c}\text { Reciclado/ } \\
\text { Coletado }\end{array}$ \\
\hline Jan/13 & 143,86 & 28,87 & 4,10 & 72,06 & 26,60 & 23,85 & - & 299,34 & $7,66 \%$ \\
\hline Fev/13 & 95,85 & 17,89 & 6,57 & 38,03 & 31,86 & 8,63 & - & 198,83 & $6,06 \%$ \\
\hline Mar/13 & 80,31 & 23,98 & 6,39 & 64,53 & 25,30 & 16,53 & 8,80 & 225,84 & $6,77 \%$ \\
\hline $\mathrm{Abr} / 13$ & 116,05 & 20,75 & 3,61 & 40,13 & 14,76 & 14,62 & - & 209,92 & $6,54 \%$ \\
\hline Mai/13 & 142,04 & 22,79 & 5,02 & 52,03 & 15,21 & 16,84 & - & 253,93 & $8,14 \%$ \\
\hline Jun/13 & 115,48 & 25,02 & 6,41 & 84,41 & 13,04 & 18,18 & - & 262,54 & $8,56 \%$ \\
\hline Jul/13 & 110,00 & 24,32 & 4,96 & 83,20 & 12,45 & 16,50 & - & 251,43 & $7,90 \%$ \\
\hline $\mathrm{Ago} / 13$ & 107,30 & 23,82 & 6,30 & 91,00 & 11,26 & 17,25 & - & 256,93 & $8,14 \%$ \\
\hline Set/13 & 83,89 & 10,35 & 3,97 & 47,78 & 10,04 & 5,41 & 3,97 & 165,41 & $4,97 \%$ \\
\hline Out/13 & 138,98 & 23,15 & 6,24 & 83,85 & 11,24 & 25,69 & - & 289,15 & $8,00 \%$ \\
\hline Nov/13 & 132,56 & 22,45 & 7,30 & 67,24 & 15,61 & 14,91 & - & 260,07 & $7,40 \%$ \\
\hline Dez/13 & 143,37 & 21,83 & 4,20 & 80,49 & 6,93 & 22,65 & - & 279,47 & $7,92 \%$ \\
\hline 2013 & 1409,69 & 265,22 & 65,07 & 804,75 & 194,30 & 201,06 & 12,77 & 2952,86 & $7,34 \%$ \\
\hline Méd. mês & 117,47 & 22,10 & 5,42 & 67,06 & 16,19 & 16,76 & 1,06 & 246,07 & - \\
\hline Méd. dia & 3,92 & 0,74 & 0,18 & 2,24 & 0,54 & 0,56 & 0,04 & 8,20 & - \\
\hline
\end{tabular}

Fonte: Felco Faleiros (2015).

A cooperativa "São José", em 2014 possuía cerca de 120 cooperados e a renda média por cooperado era de $\mathrm{R} \$ 1.200,00$, trabalhando de 5 a 6 horas por dia.

A renda para a manutenção da cooperativa em 2014 foi retirada do material que após ser coletado e triado foi vendido às empresas de reciclagem. O Quadro 4.3 apresenta o valor dos materiais recicláveis, negociados pela cooperativa em 2014.

Quadro 4.3 Materiais recicláveis negociados em 2014 em R\$/kg.

\begin{tabular}{|c|c|c|}
\hline & & Valores \\
\hline \multirow{5}{*}{ Plásticos } & PET & 2,10 \\
\hline & Mole & 0,40 \\
\hline & Duro & 1,20 \\
\hline & CD & 0,30 \\
\hline & PVC & 0,50 \\
\hline \multirow{7}{*}{ Papéis } & Papelão enfardado & 0,50 \\
\hline & Papelão solto & 0,31 \\
\hline & Papel branco & 0,45 \\
\hline & Papel arquivo & 0,45 \\
\hline & Papel misto & 0,34 \\
\hline & Revista & 0,30 \\
\hline & Jornal & 0,26 \\
\hline
\end{tabular}




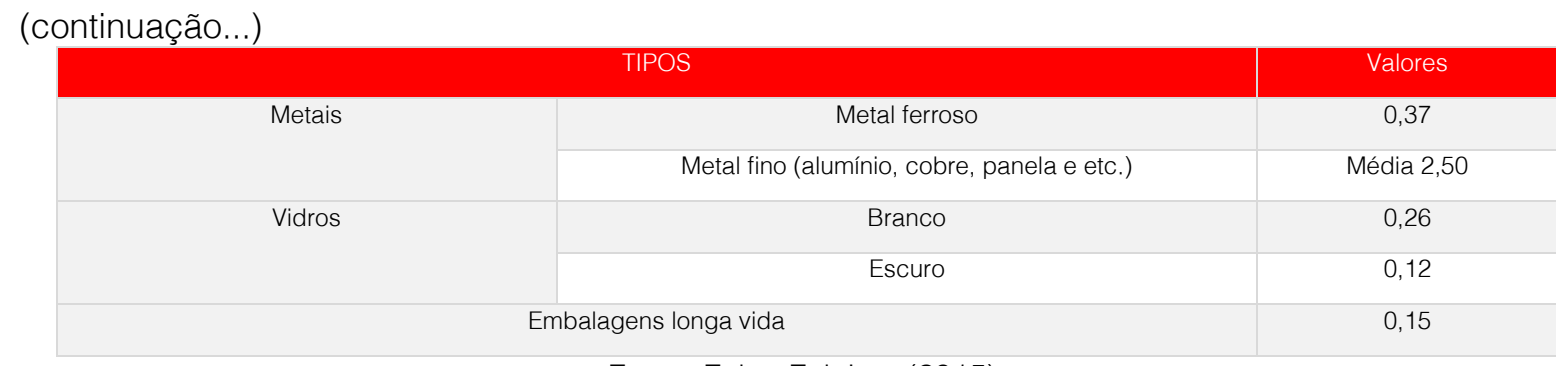

Fonte: Felco Faleiros (2015).

No mesmo ano a cooperativa enfrentava problemas com as esteiras, mesmo assim $80 \%$ da renda da cooperativa é originaria dos resíduos domiciliares e comerciais que foram triados nelas.

\subsubsection{PLANO MUNICIPAL DE SANEAMENTO BÁSICO E PLANO MUNICIPAL DE GESTÃO INTEGRADA DE RESÍDUOS SÓLIDOS DE BRAGANÇA PAULISTA-SP}

O município possui uma área de 512,584 km², uma população segundo estimativas para 2016 de 162.435 habitantes e densidade demográfica de 286,26 habitantes/km² (IBGE, 2016b).

As informações a seguir foram retiradas do Plano Municipal de Saneamento Básico do município de Bragança Paulista (B\&B ENGENHARIA, 2015).

No município de Bragança Paulista, a coleta seletiva é realizada pela empresa Embralixo Ltda. O caminhão da empresa tem capacidade para $6 \mathrm{~m}^{3}$ de armazenamento, que distribui os resíduos coletados para as cooperativas Bragança Recicla e Recicle Bragança. Porém, o trabalho realizado só atende $20 \%$ do município.

O recolhimento foi de $5,02 \mathrm{~kg}$ de materiais recicláveis por habitante por ano, produzindo 750 toneladas por ano, totalizando cerca de $1,2 \%$ do total de resíduos gerados no município (B\&B ENGENHARIA, 2015).

As Cooperativas reciclam 16 tipos de materiais: PET, PP Branco, PP Colorido, PS, ABS, PVC, PVC Encolhível, Papel Branco, Papel Misto, Papelão, TetraPak, Vidro Branco, Vidro Colorido, Alumínio, Ferro e Lâmpadas.

A Cooperativa Bragança Recicla tem 16 cooperados que contam com os seguintes materiais para realizar a triagem: uma esteira elevatória; uma esteira de triagem $(15 \mathrm{~m} \times 0,9 \mathrm{~m})$; uma prensa hidráulica; um veículo automotivo Kombi; e bags.

A Cooperativa Recicle Bragança também recebe o material coletado para realizar a triagem. Esta cooperativa tem 10 cooperados e realiza a triagem com os seguintes materiais: uma prensa hidráulica; uma bancada de madeira; um veículo automotivo Saveiro com gaiola; e bags.

No Quadro 4.4, constam os equipamentos disponíveis, às cooperativas conveniadas ao município de Bragança Paulista-SP, para realizar a triagem dos resíduos sólidos.

Quadro 4.4 Equipamentos disponíveis para realizar a triagem no município de Bragança Paulista-SP.

\begin{tabular}{|c|c|}
\hline Equipamentos & Quantidade \\
\hline Esteira elevatória & 1 \\
\hline Esteira de triagem (15 metros x 0,9 metros) & 1 \\
\hline Prensa Hidráulica & 2 \\
\hline Veículo Saveiro com gaiola & 1 \\
\hline Veículo Kombi & 1 \\
\hline
\end{tabular}

Fonte: B\&B Engenharia (2015). 
De acordo com o Relatório da Coleta Seletiva 2013, elaborado pela Secretaria Municipal de Meio Ambiente (SMMA) de Bragança Paulista, o município apresentou na Quadro 4.5 a relação de quantitativos de materiais recicláveis entre janeiro e agosto de 2013.

Quadro 4.5 Informações quantitativas e qualitativas de resíduos recicláveis gerenciados nos meses de janeira a agosto de 2013.

\begin{tabular}{|c|c|c|}
\hline Resíduo Gerado & Tipo & Quantidade (ton/mês) \\
\hline Papel & $\begin{array}{c}\text { Papel de terceira (jornais, revistas, etc.) e papel arquivo } \\
\text { branco. }\end{array}$ & 16,5 \\
\hline Papelão & Papelão ondulado 1 e papelão ondulado 2. & 23,0 \\
\hline Plástico & $\begin{array}{l}\begin{array}{l}\text { Aparas de plástico colorido e branco; plástico PP, plástico } \\
\text { PET, }\end{array} \\
\begin{array}{l}\text { plástico PEAD, plástico PS, plástico ABS, plástico PVC, } \\
\text { plástico }\end{array} \\
\text { PEBD, plástico ABS/PC, entre outros (menor quantidade). }\end{array}$ & 13,0 \\
\hline Metal & $\begin{array}{l}\text { Ferro, cobre, alumínio, latão (cobre + zinco), entre outros } \\
\text { (menor quantidade). }\end{array}$ & 5,0 \\
\hline Vidro & Garrafas e cacos. & 8,0 \\
\hline
\end{tabular}

Fonte: B\&B Engenharia (2015)

Os resíduos sólidos triados, triturados ou prensados em fardos e armazenados pelas Cooperativas que atuam em Bragança Paulista são comercializados, com as indústrias da região especializadas em reciclagem de papel, papelão, plásticos e alumínio, dentre outras, com certa dificuldade devido à baixa quantidade ainda coletada.

Não existem estudos precisos sobre o potencial de aproveitamento dos resíduos recicláveis na região, porém, acredita-se que o potencial está muito além do que vem sendo coletado e aproveitado pelas cooperativas atuantes em Bragança Paulista.

\subsubsection{PLANO MUNICIPAL DE SANEAMENTO BÁSICO E PLANO MUNICIPAL DE GESTÃO INTEGRADA DE RESÍDUOS SÓLIDOS DE ITATIBA-SP}

O município de Itatiba possui área territorial de $322,27 \mathrm{~km}^{2}$ e a estimativa populacional para 2016 é de 114.921 habitantes e densidade demográfica de 314,90 hab/km² (IBGE, 2016c).

As informações a seguir foram retiradas do Plano Municipal de Saneamento Básico e Plano Municipal de Gestão Integrada de Resíduos Sólidos de Itatiba-SP (N S ENGENHARIA, 2016).

De acordo com o PMSB e PMGIRS (N S ENGENHARIA, 2016), a coleta seletiva atende $100 \%$ do município de Itatiba e encaminha para a cooperativa "Reviver".

A cooperativa tem à disposição três esteiras para realizar a triagem, que é realizada por 11 a 13 cooperados. Após encherem os "bags" o encaminham para serem prensados, nas duas prensas que estão à disposição da cooperativa.

A Cooperativa "Reviver", no ano de 2014 foram reciclados os seguintes materiais apresentados no Quadro 4.6, estes que geraram uma renda de $R \$ 464.909,48$. 
Quadro 4.6 Quantitativo de material reciclado em 2014.

\begin{tabular}{|c|c|}
\hline Material & Quantidade \\
\hline Papel e papelão & 502,03 \\
\hline Plástico & 184,52 \\
\hline Metais & 80,12 \\
\hline Vidros & 181,41 \\
\hline Alumínio & 9,56 \\
\hline Outros & 74,98 \\
\hline Total & $1.032,62$ \\
\hline
\end{tabular}

Fonte: Prefeitura do Município de Itatiba (2014).

De acordo com a Secretaria de Meio Ambiente e Agricultura, as despesas relacionadas à coleta seletiva no ano de 2014 foram $\mathrm{R} \$ 1.753 .252,64$.

\subsection{ATIVIDADE DE RESOLUÇÃO DE PROBLEMAS}

As atividades de Resolução de Problemas permitem explorar uma infinidade de resoluções, no entanto, é preciso que os alunos soltem a imaginação e não fiquem presos a uma resolução padrão. É importante evidenciar que existem mais de uma maneira de achar soluções, desde que é claro respeitem as regras Matemáticas e os conceitos matemáticos (POLYA, 1995).

Na Figura 4.1 estão apresentadas as quatro etapas do MRP, que ajudam a organizar o raciocínio e a encontrar a solução dos problemas.

Figura 4.1 Etapas do Método de Resolução de Problemas.

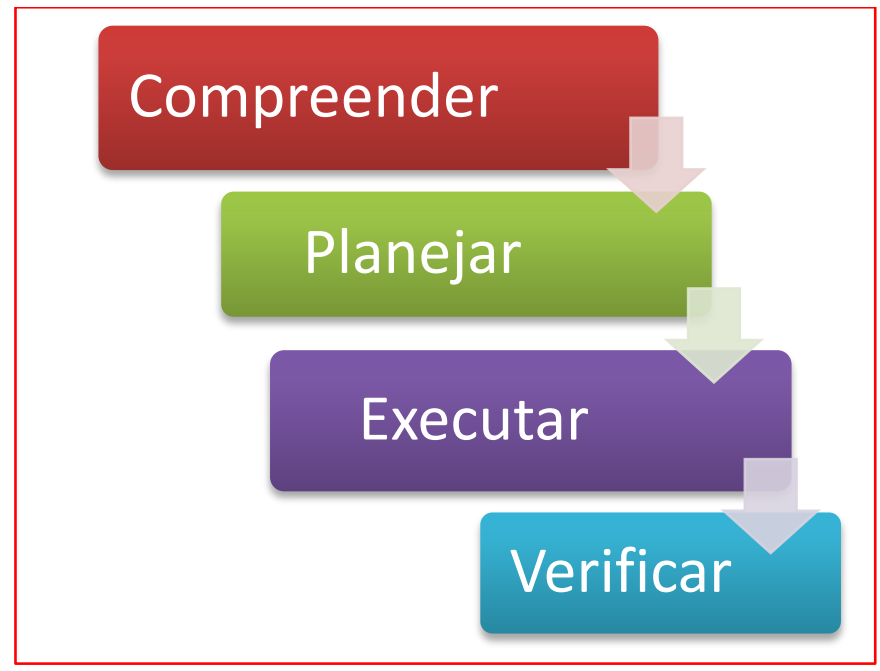

Fonte: Polya (1995)

Estas etapas são as que orientam o processo de resolução das atividades que foram criadas, a partir das informações da coleta seletiva, para explorar conteúdos e conceitos matemáticos. As atividades criadas estão apresentadas nos itens 4.2.1, 4.2.2, 4.2.3, 4.2.4, 4.2.5, 4.2.6, 4.2.7 e 4.2.8. 


\subsubsection{ATIVIDADE 1 - PROPORÇÃO 1ํ ANO DO EM}

O Quadro 1 apresenta a quantidade, em toneladas, de materiais reciclados ao longo do ano de 2013.

Quadro 1 Resíduos reciclados em 2013, em toneladas.

\begin{tabular}{|c|c|}
\hline Período mês/ano & Reciclado (ton.) \\
\hline Jan/13 & 299,34 \\
\hline Fev/13 & 198,83 \\
\hline Mar/13 & 225,84 \\
\hline Abr/13 & 209,92 \\
\hline Mai/13 & 253,93 \\
\hline Jun/13 & 262,54 \\
\hline Jul/13 & 251,43 \\
\hline Ago/13 & 256,93 \\
\hline Set/13 & 165,41 \\
\hline Out/13 & 289,15 \\
\hline Nov/13 & 260,07 \\
\hline Dez/13 & 279,47 \\
\hline
\end{tabular}

Fonte: Felco Faleiros (2015).

O município de Atibaia, em 2013, reciclou 7,34\% do total de material coletado. Quantas toneladas de resíduos foram coletados em 2013 ?

\section{I-Entendendo o problema:}

No ano de 2013 foi coletado uma quantidade $x$ de resíduos, deste valor, apenas 7,34\% foi reciclado. O problema quer determinar o valor de $x$.

\section{II-Estabelecendo um plano:}

A tabela apresenta as quantidades que foram recicladas em cada mês de 2013, portanto ao realizar a soma dessas quantidades podemos obter o total de resíduos reciclados em 2013. Em seguida, podemos igualar o total de resíduos reciclados a 7,34\% do valor $x$.

III-Colocando o plano em prática:

A soma das quantidades do Quadro 1, resulta em 2952,86 toneladas, que representam a quantidade de resíduos reciclados em 2013.

Pode-se definir que:

$$
\begin{gathered}
\frac{7,34}{100} x=2952,86 \\
x=2952,86 \times \frac{100}{7,34} \\
x \cong 40229,7
\end{gathered}
$$

Por fim, obtêm-se como valor de $x, 40.229,7$ toneladas, que corresponde ao valor coletado em 2013. 


\section{IV-Revendo os passos:}

Esta atividade permite trabalhar com o conceito de porcentagem, dentro do conteúdo de proporção. No momento de definir o total de material triado, é possível que alguns alunos não percebam que a soma das partes do quadro representa isto. No entanto, é um raciocínio fácil de incentivar, pode-se perguntar, por exemplo, qual a utilidade dos dados do quadro.

\subsubsection{ATIVIDADE 2 - PROGRESSÃO GEOMÉTRICA 1ํANO DO EM}

Em 2014 foram reciclados na cooperativa "Reviver" um total de 1.050 toneladas de resíduos sólidos, que resultou em uma renda de $\mathrm{R} \$ 460.000,00$.

Suponha que a cooperativa fez um acordo com as empresas de reciclagem para manter os valores de venda por cinco anos e que o total de resíduos reciclados dobre a cada ano. Em que ano a cooperativa reciclará mais de quinze mil toneladas de resíduos? Qual será o valor arrecadado neste ano?

\section{I-Entendendo o problema:}

A cooperativa arrecadou 460 mil reais, em 2014, com a venda de 1.050 toneladas de resíduos reciclados. Como os resíduos dobram a cada ano em 2015, por exemplo, o total de resíduos será de 2.100 toneladas e assim por diante. Então pode-se perceber um crescimento geométrico de razão 2 . Entre 2014 e 2018 a quantidade de material reciclado superou 15 mil toneladas, o problema quer identificar em que ano isto ocorreu. Além disso, descobrir quanto foi arrecadado neste ano, sabendo que os valores de venda serão preservados por cinco anos, ou seja, o preço da tonelada de resíduos sólidos em 2018 ainda será o mesmo de 2014.

II-Estabelecendo um plano:

Para descobrir em que ano atingiu-se 15 mil toneladas de material reciclado, pode-se calcular por meio de progressão geométrica, onde o primeiro termo é 1.050 e a razão é 2. No entanto, não se sabe qual termo se busca, então deve-se calcular para um termo aleatório, em seguida, caso não seja o termo procurado, pode-se decidir calcular para o termo anterior ou o sucessor. Após descoberto o ano, verificar se este encontra-se entre 2014 e 2018 para definir o valor da renda.

\section{III-Colocando o plano em prática:}

Temos a progressão geométrica: $(1.050,2.100, \ldots)$, pode-se escolher o termo $a_{4}$, por exemplo. Seguindo a progressão obtêm-se: $(1.050,2.100,4.200,8.400, \ldots)$, logo $a_{4}=8400$, conclui-se que o termo procurado está acima. Pode-se testar para $a_{5}$, que na progressão equivale a 16.800 , ou seja, a quantidade de reciclados foi superior a quinze mil, logo este é o termo procurado.O termo $a_{5}$ equivale ao ano de 2018, que está na margem do acordo. Portanto pode-se encontrar o valor da renda por meio de regra de três, onde:

$$
\begin{gathered}
1050 \leftrightarrow 460.000 \\
16.800 \leftrightarrow x \\
x=7.360 .000
\end{gathered}
$$

Portanto, conclui-se que a renda no ano de 2018 foi de $\mathrm{R} \$ 7.360 .000,00$

\section{IV-Revendo os passos:}

Ao supor os termos da progressão geométrica o aluno desenvolve a capacidade de comparação. Esta atividade permite trabalhar conceitos de progressão geométrica. Além disso, é possível fazer o aluno perceber a utilidade em prever situações.

\subsubsection{ATIVIDADE 3 - ESTIMATIVA E PORCENTAGEM 1ํANO DO EM}

Os resíduos reciclados no ano de 2013 em Bragança Paulista-SP basicamente foram: papel, papelão, plástico, metal e vidro. O Quadro 2, apresenta a quantidade de toneladas por mês de cada um desses materiais. 
Quadro 2 Quantidade de materiais reciclados, em toneladas, em 2013.

$\begin{array}{cc}\text { Resíduo Gerado } & \text { Quantidade (ton/mês) } \\ \text { Papel } & 16,5 \\ \text { Papelão } & 23,0 \\ \text { Plástico } & 13,0 \\ \text { Metal } & 5,0 \\ \text { Vidro } & 8,0 \\ \text { Fonte: B\&B Engenharia (2015). }\end{array}$

Em 2013, o município de Bragança Paulista possuía 146.800 habitantes, e a coleta seletiva atendia apenas $20 \%$ da população. A estimativa da população para 2016 é de 162.400 habitantes e a coleta seletiva passou a atender $40 \%$ da população.

O secretario de meio ambiente do município deseja estimar quantas toneladas de materiais podem ser reciclados em 2016.

\section{I-Entendendo o problema:}

O secretario deseja descobrir a estimativa de materiais reciclados em $2016 \mathrm{com}$ base nos dados de 2013.

\section{Il-Estabelecendo um plano:}

A partir do quadro é possível determinar quantas toneladas de materiais foram reciclados em 2013 , basta somar os valores do Quadro e multiplicar por 12. Essa quantidade foi produzida por $20 \%$ da população de 2013. Já em 2016 foi produzida uma quantidade x por 40\% da população. Então ao estabelecer as porcentagens da população de 2013 e 2016 é possível relacionar com a quantidade de reciclados de 2013.

\section{III-Colocando o plano em prática:}

Calculando a soma do Quadro, obtêm-se 65,5 toneladas por mês, que multiplicado por 12, para saber a quantidade do ano, resulta em 786 toneladas. Ao calcular $20 \%$ de 146.800 hab., obtêm-se 29.360 habitantes, estes correspondem a quantidade de materiais reciclados em 2013 Ao calcular 40\% de 162.400 hab., obtêm-se 64.960 habitantes.

Logo, obtêm-se a seguinte correspondência:

$$
\begin{gathered}
29.360 \text { hab } \leftrightarrow 786 \text { ton } \\
64.960 \text { hab } \leftrightarrow x \text { ton } \\
x=\frac{786 \times 64960}{29360} \\
x=1739 \text { ton }
\end{gathered}
$$

Portanto, conclui-se que em 2016 serão reciclados 1.739 toneladas de materiais.

\section{IV-Revendo os passos:}

Nesta resolução os alunos podem encontrar dificuldades em encontrar a quantidade triada no ano, tem de haver a percepção de que um ano equivale a 12 meses. Além disso, calcular as porcentagens significa, nesse caso, indicar qual parcela da população contribuiu para a reciclagem. 


\subsubsection{ATIVIDADE 4 - PROGRESSÃO ARITMÉTICA 1ํ ANO DO EM}

Em janeiro de 2013, no município de Atibaia-SP, foram recicladas 28 toneladas de sucata. Suponha que, cada cooperado ganhou um bônus por reciclar durante $\mathrm{o}$ ano, cinco toneladas a mais do que no mês anterior.

Para estabelecer o valor do bônus o administrador da cooperativa precisa determinar: quantas toneladas foram recicladas no mês de dezembro de 2013 , e, quantas toneladas foram recicladas no ano de 2013.

O bônus $(B)$ será calculado de acordo com a seguinte equação:

$$
B=1,85 \times D+0,5 \times A
$$

Onde $D$ equivale ao reciclado em dezembro e $A$ equivale ao que foi reciclado no ano de 2013.

\section{I-Entendendo o problema:}

A quantidade de sucata recebeu um acréscimo de cinco toneladas em cada mês durante o ano de 2013. Isso representa uma progressão aritmética de razão cinco, onde o primeiro termo é 28, que representa a quantidade de sucata reciclada em janeiro do referido ano. O problema pretende identificar quantas toneladas foram recicladas no mês de dezembro, e quantas toneladas foram recicladas ao longo do ano, para que com esses valores, calcule-se o bônus $(B)$.

\section{II-Estabelecendo um plano:}

O termo $a_{1}$ da progressão aritmética equivale ao 28 , o termo $a_{12}$ equivale a $D$. E a soma dos termos $a_{1}$ à $a_{12}, S_{12}$, equivale a $A$. Portanto basta calcular o termo $a_{12}$ e a soma $S_{12}$ e substituir na fórmula para obter o valor do bônus.

\section{III-Colocando o plano em prática:}

Pode-se calcular $D$, por meio da fórmula de termos da P.A.:

$$
\begin{gathered}
a_{12}=28+5 \times 11 \\
a_{12}=83
\end{gathered}
$$

Por outro lado, para calcular $S_{12}$, pode-se utilizar a soma de termos finitos da P.A.:

$$
\begin{gathered}
S_{12}=\frac{(28+83) \times 12}{2} \\
S_{12}=666
\end{gathered}
$$

Assim, com $D$ e $A$ determinados, substituindo-os em $B$, obtêm-se:

$$
\begin{gathered}
B=1,85 \times 83+0,5 \times 666 \\
B=486,55
\end{gathered}
$$

Portanto, o bônus que cada cooperado recebeu foi de $\mathrm{R} \$ 486,55$. 


\section{IV-Revendo os passos:}

Tanto ao calcular o termo $a_{12}$, quanto ao calcular o $S_{12}$ é possível utilizar a dedução para determinar as fórmulas, isso pode gerar um maior significado para o aluno. Além disso, pode-se explorar 0 problema, procurando identificar quantos cooperados participaram do recebimento do bônus, ou ainda encontrar maneiras distintas de alcançar a solução.

\subsubsection{ATIVIDADE 5 - ÁLGEBRA 2ํ ANO DO EM}

Um container tem capacidade para 32 fardos. O Quadro 3 contém as informações referentes ao peso em quilos de um fardo de cada um dos materiais reciclados na cooperativa "Recicle Bragança".

Quadro 3 Peso (em quilos) de um fardo prensado.

\begin{tabular}{|c|c|}
\hline Fardo & Peso $(\mathrm{kg})$ \\
\hline Papel & 300 \\
\hline Papelão & 200 \\
\hline Plástico & 170 a 300 \\
\hline Metal & 350 \\
\hline Vidro & - \\
\hline
\end{tabular}

Fonte: Cooperativa Recicle Bragança (2016).

Suponha que um contêiner foi carregado com Papel e Papelão e, o funcionário responsável perdeu as contas de quantos fardos de cada material foram colocados no container. Ele precisa dessa informação para digitar no sistema. Sabe-se que o container lotado pesa 8,1 toneladas. Como o funcionário pode resolver a situação?

\section{I-Entendendo o problema:}

Um funcionário precisa saber quantos fardos de papel e quantos de papelão, estão dentro de um container. Sabe-se que no container cabem 32 fardos e de acordo com a tabela, um fardo de papel pesa 300 quilos e um fardo de papelão pesa 200 quilos. Além disso, o peso do container carregado é de 8100 quilos. Quantos fardos de papel estão dentro do container? Quantos de papelão?

II-Estabelecendo um plano:

Sabemos que existe certo número de fardos de papel (a) que somados ao total de fardos de papelão $(b)$ resultam no peso máximo do container, conforme a Equação 1.

$$
300 a+200 b=8100
$$

Equação 1

Portanto, da Equação 1 obtemos a como o número de fardos de papel e $b$ os fardos de papelão.

Por outro lado, sabemos que a capacidade máxima do container é de 32 fardos, logo a soma dos fardos de papel e papelão é igual a 32, conforme a Equação 2.

$$
a+b=32
$$

\section{Equação 2}




\section{1}

Com essas informações é possível encontrar os valores de $a$ e $b$ por meio de um sistema linear.

III-Colocando o plano em prática:

Da Equação 1 e da Equação 2, obtemos um sistema linear, conforme a Figura 1.

Figura 1: Sistema Linear

$$
\left\{\begin{array}{c}
300 a+200 b=8100 \\
a+b=32
\end{array}\right.
$$

A partir da Equação 2, obtemos a Equação 3.

$$
b=32-a
$$

Equação 3

Substituindo o resultado da Equação 4 na Equação 1, obtemos o valor de a, conforme a Figura 2.

Figura 2: Valor de a.

$$
\begin{gathered}
300 a+200(32-a)=8100 \\
300 a+(6400-200 a)=8100 \\
100 a=8100-6400 \\
100 a=1700 \\
a=17
\end{gathered}
$$

Portanto, há 17 fardos de papel no container, logo faltam 15 fardos de papelão para completar a lotação do container, que é de 32 fardos. Então 15 é o número de fardos de papelão $(b)$.

\section{IV-Revendo os passos:}

No primeiro momento, foi necessário reunir as informações que estavam dispostas no problema. Essas informações compreendiam em trabalhar com as totalidades de fardos e peso, que o container suportava. A partir disso, ao cruzar as informações foram obtidos os resultados, que são coerentes com as informações dadas, conforme a Figura 3.

Figura 3 Confirmando o resultado.

$$
300 \times 17+200 \times 15=8100
$$

No entanto, é possível resolver o sistema de outras maneiras, inclusive é possível resolver o problema por tentativa e erro, uma possibilidade para os alunos que não conhecem sistemas lineares. 


\subsubsection{ATIVIDADE 6 - GEOMETRIA ESPACIAL 2ํㅜ ANO DO EM}

$\mathrm{Na}$ cooperativa Reviver, os fardos de um tipo de plástico têm altura, largura e comprimento, respectivamente, $80 \mathrm{~cm}, 100 \mathrm{~cm}$ e $80 \mathrm{~cm}$.

Uma empresa que recicla esse material enviou um contêiner que tem altura, largura e comprimento, respectivamente, $2 \mathrm{~m}, 5 \mathrm{~m}$ e $8 \mathrm{~m}$. Quantos fardos cabem no contêiner?

\section{I-Entendendo o problema:}

Os cooperados devem lotar um contêiner que tem 2 metros de altura, 5 metros de largura e 8 metros de comprimento, com fardos que tem 0,8 metros de altura, 0,8 metros de largura e 1 metro de comprimento. Quantos fardos devem caber, respeitando as medidas apresentadas? É importante lembrar que cabe interpretação quanto à posição do fardo. Portanto, pode-se encontrar mais de uma resposta.

Esta atividade envolve conceitos geométricos, portanto, é uma oportunidade para trabalhar com desenhos e explorar a imaginação. Neste caso, começaremos desenhando um contêiner, como na Figura 4.

Figura 4 Contêiner.

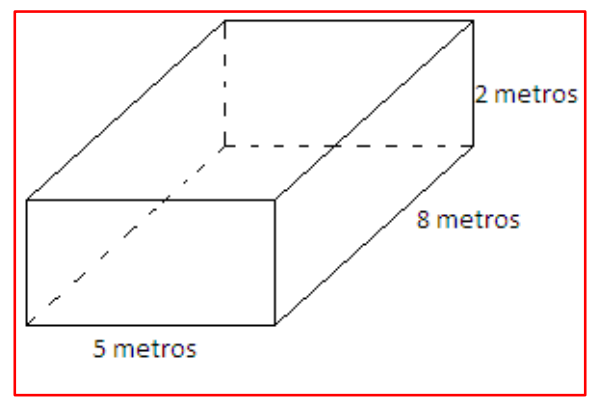

Fonte: Elaborado pelo autor.

Em seguida desenhamos um fardo, dentro do modelo de contêiner apresentado na Figura 1, indicando as medidas informadas, como na Figura 5.

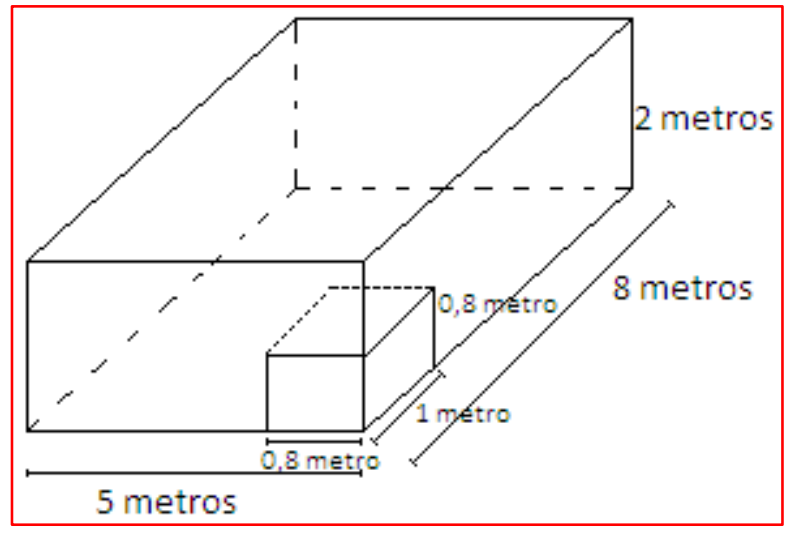

Fonte: Elaborado pelo autor.

\section{II-Estabelecendo um plano:}

Para fins de estabelecer um plano vamos tomar como posição do fardo, a que está descrita no problema que é a posição da Figura 5. Logo temos que definir qual a relação entre a altura, largura e comprimento do contêiner e de um fardo. 
Para a altura temos que descobrir quantos fardos de altura 0,8 metros cabe na altura do contêiner que é de 2 metros. E prosseguir da mesma maneira para a largura e o comprimento. Após obter essas informações é possível saber quantos fardos conseguimos colocar dentro do contêiner respeitando as dimensões dadas.

\section{III-Colocando o plano em prática:}

Sabendo que a altura do contêiner é de 2 metros e a altura do fardo é de 0,8 metros, chegamos à conclusão que cabem apenas dois fardos que resultam em 1,6 metros de altura. Caso fossem colocados três fardos teríamos como altura 2,4 metros e isso excede a altura do contêiner em 0,4 metros. Portanto dois fardos são suficientes, conforme o cálculo a seguir:

$$
\begin{aligned}
& 2=2 \times 0,8+0,4 \\
& 2=1,6+0,4
\end{aligned}
$$

Em relação à largura, sabe-se que o contêiner tem 5 metros e o fardo tem 0,8 metros, logo, pode-se concluir que serão suficientes 6 fardos que resultam em 4,8 metros, conforme o cálculo a seguir:

$$
\begin{aligned}
& 5=6 \times 0,8+0,2 \\
& 5=4,8+0,2
\end{aligned}
$$

Seguindo o mesmo raciocínio devemos concluir que para preencher os 8 metros de comprimento do contêiner serão necessários oito fardos, já que cada fardo tem um metro de comprimento.

Com isso concluímos que para:

Altura são necessários 2 fardos;

Largura são necessários 6 fardos; e,

Comprimento são necessários 8 fardos.

Logo para preencher o contêiner:

$$
2 \times 6 \times 8=96
$$

Portanto, os cooperados deverão conseguir colocar 96 fardos no contêiner.

\section{IV-Revendo os passos:}

Considerando a posição do fardo, esta atividade permite explorar o problema. Pode-se pedir para que os alunos definam qual posição do fardo, lota mais o contêiner. Além disso, a questão de levar em conta as proporções das medidas, considerando que sobram espaços, é importante, uma vez que, por exemplo não se pode dividir o fardo em partes para ocupar o máximo de espaço possível. O fardo deve preservar suas dimensões, assim como o contêiner.

\subsubsection{ATIVIDADE 7 - ESTATÍSTICA 3ANO DO EM}

Os dados abaixo foram baseados na Tabela 4.2 do item 4.1.1 deste trabalho. Esses referem-se as quantidades (em toneladas) de alumínio reciclados em Atibaia-SP, em 2013, e estão apresentadas no Quadro 4 . 
Quadro 4 Quantidade, em toneladas, de alumínio reciclado no município de Atibaia-SP em 2013.

\begin{tabular}{|c|c|c|c|c|c|c|c|c|c|c|c|}
\hline Jan & Fev & Mar & Abr & Mai & Jun & Jul & Ago & Set & Out & Nov & Dez \\
\hline 4 & 7 & 6,5 & 3,5 & 5 & 6,5 & 5 & 6,5 & 4 & 6 & 7,5 & 4 \\
\hline \multicolumn{10}{c}{ Fonte: Adaptado de Felco Faleiros (2015). }
\end{tabular}

Um gestor público está preparando uma apresentação para mostrar a evolução da reciclagem de alumínio ao longo do ano de 2013. No entanto recebeu os dados desorganizados, por isso quer colocá-los em uma tabela, para facilitar a leitura dos mesmos. Em seguida, pretende determinar a frequência, a frequência acumulada, a proporção, a proporção acumulada e a porcentagem.

\section{I-Entendendo o problema:}

O gestor precisa organizar os dados em uma tabela, pois realizará uma apresentação. A partir da tabela, determinará a frequência $\left(\boldsymbol{f}_{\boldsymbol{i}}\right)$, a frequência acumulada $\left(\boldsymbol{F}_{\boldsymbol{i}}\right)$, a proporção $\left(\boldsymbol{p}_{\boldsymbol{i}}\right)$, a proporção acumulada $\left(P_{i}\right)$ e a porcentagem $(\%)$.

\section{Il-Estabelecendo um plano:}

Para começar deve-se ordenar os dados determinando a frequência de cada um dos elementos, ou seja, quantas vezes se repetem cada um dos valores apresentados. Em seguida, esboçar uma tabela, com nove linhas e duas colunas. Uma coluna para os valores, em toneladas, de alumínio e na outra coluna a frequência. Lembrando que essencialmente uma tabela possui, título, corpo, cabeçalho e a coluna principal.

Depois de elaborada a tabela, adicionar mais quatro colunas, para a frequência acumulada, proporção, proporção acumulada e a porcentagem. Estas são determinadas com base nas informações da coluna de frequência.

\section{III-Colocando o plano em prática:}

$\mathrm{Na}$ Tabela 1 são apresentados os dados organizados (representados na primeira coluna) e as suas respectivas frequências (representadas na segunda coluna).

Tabela 1 Distribuição da quantidade de alumínio, em toneladas, triados em 2013.

\begin{tabular}{cc|} 
Alumínio (ton.) & $\boldsymbol{f}_{\boldsymbol{i}}$ \\
7,5 & 1 \\
7,0 & 1 \\
6,5 & 3 \\
6,0 & 1 \\
5,0 & 2 \\
4,0 & 3 \\
3,5 & 1 \\
Total & 12
\end{tabular}

Fonte: Adaptado de Felco Faleiros (2015).

A partir de $\boldsymbol{f}_{\boldsymbol{i}}$, se obtém $\boldsymbol{F}_{\boldsymbol{i}}$, que é a soma das frequências das classes inferiores ou iguais a $i$.

Por meio de $\boldsymbol{f}_{\boldsymbol{i}}$, também é possível obter $p_{\boldsymbol{i}}$, que é determinada por:

$$
p_{i}=\frac{f_{i}}{n}
$$


onde, $n$ é o valor da amostra, no caso, vale 12 .

A partir de $\boldsymbol{p}_{\boldsymbol{i}}$, obtém-se $\boldsymbol{P}_{\boldsymbol{i}}$, que é a soma das classes inferiores de $\boldsymbol{p}_{\boldsymbol{i}}$.

E por fim, a partir de $\boldsymbol{p}_{\boldsymbol{i}}$, obtêm-se a porcentagem.

Por fim, obtêm-se a Tabela 2.

Tabela 2 Distribuição da quantidade de alumínio, em toneladas, triados em 2013.

\begin{tabular}{|c|c|c|c|c|c|}
\hline Alumínio (ton.) & $\boldsymbol{f}_{\boldsymbol{i}}$ & $\boldsymbol{F}_{\boldsymbol{i}}$ & $\boldsymbol{p}_{\boldsymbol{i}}$ & $\boldsymbol{P}_{\boldsymbol{i}}$ & $\%$ \\
\hline 7,5 & 1 & 1 & 0,08 & 0,08 & 8 \\
\hline 7,0 & 1 & 2 & 0,08 & 0,16 & 25 \\
\hline 6,5 & 3 & 5 & 0,25 & 0,41 & 8 \\
\hline 6,0 & 1 & 6 & 0,08 & 0,49 & 17 \\
\hline 5,0 & 2 & 8 & 0,17 & 0,66 & 25 \\
\hline 4,0 & 3 & 11 & 0,25 & 0,91 & 8 \\
\hline 3,5 & 1 & 12 & 0,08 & 1 & 100 \\
\hline
\end{tabular}

Fonte: Adaptado de Felco Faleiros (2015).

A Tabela 2 contém todas as informações exigidas pelo gestor, para a sua apresentação.

\section{IV-Revendo os passos:}

Os dados que estavam fora de ordem, foram organizados conforme a Tabela 2. Além disso, a partir dos dados inicialmente informados, foram determinadas as frequências que foram úteis para determinar a frequência acumulada, a proporção, a proporção acumulada e a porcentagem. Nesta atividade, uma sugestão é deixar os alunos livres quanto a construção das tabelas e dos gráficos, num momento inicial, para gerar conflitos. Num segundo momento é possível, por meio de comparação, mostrar que é necessário estabelecer um padrão, para que sempre consiga uma mesma interpretação ou visualização dos gráficos e das tabelas.

\subsubsection{ATIVIDADE 8 - ESTATÍSTICA 3ำ ANO DO EM}

Mesmo após a tabulação dos dados, realizada no item 4.2.3, o gestor público não ficou satisfeito e resolveu fazer um gráfico com as informações das quantidades de alumínio, que fornecidas no Quadro 4.

\section{I-Entendendo o problema:}

No item 4.2.3, foram fornecidas as quantidades de alumínio em cada um dos meses de 2013 do município de Atibaia no Quadro 4, e o gestor resolveu construir um gráfico, utilizando estas informações.

\section{II-Estabelecendo um plano:}

Para esta atividade devemos usar o gráfico de barras. Para a construção do gráfico pode-se colocar os meses no eixo horizontal e as quantidades de alumínio na vertical. Em seguida deve-se graduar o eixo vertical proporcionalmente aos valores fornecidos no Quadro 4.

\section{III-Colocando o plano em prática:}

A Figura 6 apresenta o gráfico que foi construído com base no Quadro 4, com os meses no eixo horizontal e as quantidades de alumínio no eixo vertical. 
Figura 6 Quantidade de Alumínio reciclado no município de Atibaia em 2013, em toneladas.

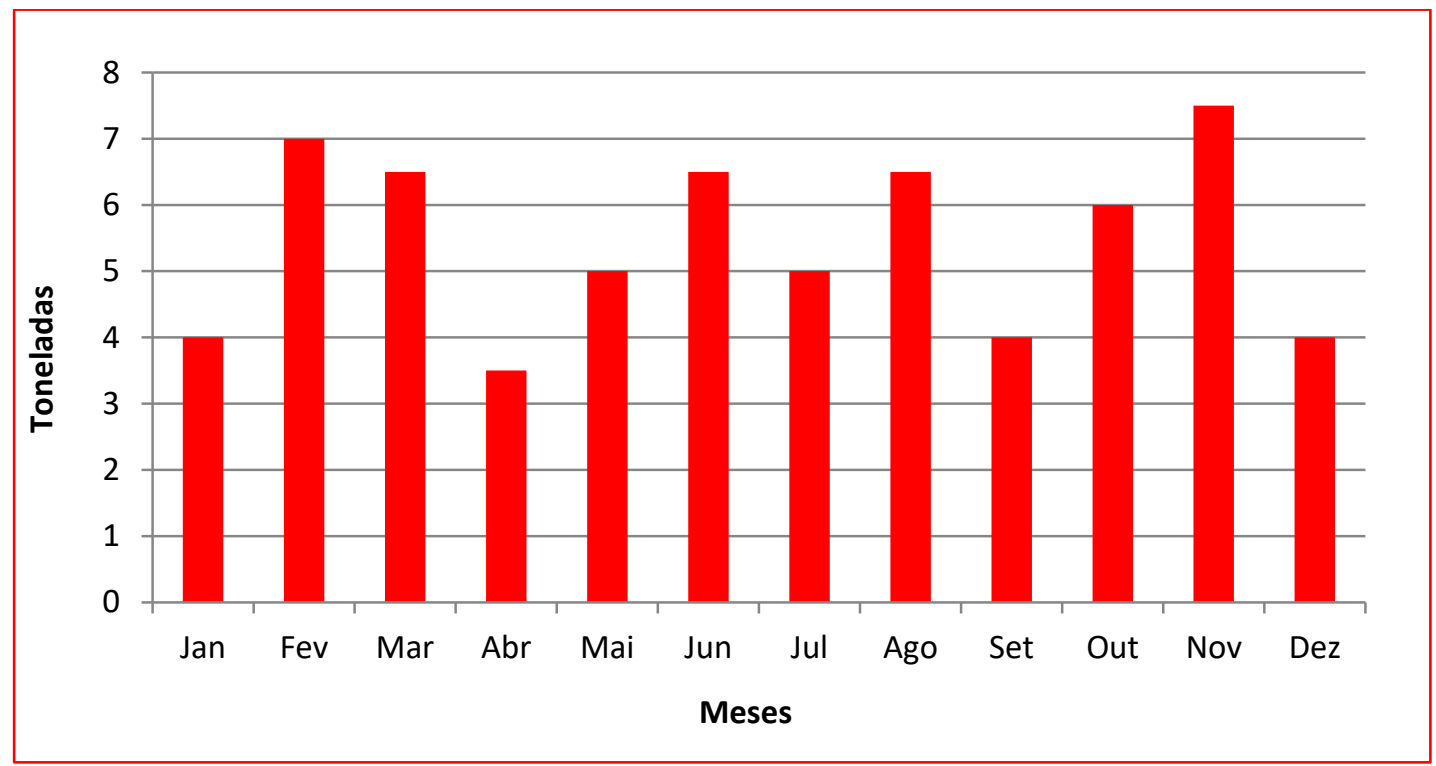

Fonte: Elaborado pelo autor.

\section{IV-Revendo os passos:}

Foi necessário definir quais informações deveriam ficar na horizontal e na vertical do gráfico, em seguida, graduá-las, para enfim, dispor as informações fornecidas. A construção de gráficos envolve trabalhar com associação de informações. O aluno deve conhecer os gráficos, para decidir qual utilizar. Além disso, deve possuir uma noção geométrica, uma vez que, necessita associar os pontos.

Os dados extraídos do contexto da coleta seletiva fundamentaram distintas situações-problema que forneceram espaço para a representação de conceitos matemáticos.

Assim, verificou-se durante a solução das atividades o potencial do MRP, para divagar sobre as possibilidades que envolvem as soluções.

Por fim, as atividades foram desenvolvidas na intenção de contribuir com o ensino de conteúdos e conceitos matemáticos. As soluções, encontradas por meio do MRP, apontam que apesar das interpretações e maneiras de resolver as atividades, a reflexão sobre essas possibilidades tem um intenso potencial de ensinar.

\subsection{BREVE RESUMO DO CAPÍTULO}

Este capítulo apresentou os dados coletados e em seguida de que maneira eles foram tratados e serviram de subsídio para criar as atividades que são apresentadas, as quais foram solucionadas utilizando o Método de Resolução de Problemas (MRP). 


\section{Capítulo 5}

Conclusões 


\section{CONCLUSÕES}

Neste capítulo são apresentadas as conclusões do trabalho, as considerações finais, as limitações da pesquisa e as propostas de trabalhos futuros.

\subsection{CONCLUSÕES}

A pesquisa realizou um levantamento na perspectiva educativa, visando ampliar as possibilidades de ensinar conteúdos matemáticos atender ao problema proposto: "Os dados da Coleta Seletiva da Microrregião de Bragança Paulista são úteis na proposta de elaboração de atividades didáticas de Resolução de Problemas, que visem o ensino de Álgebra, Aritmética, Estatística e Geometria, para as séries do Ensino Médio?". Desse modo, a principal conclusão deste trabalho, que confirma a hipótese inicial, é de que os dados extraídos do contexto da Coleta Seletiva, são úteis na elaboração de atividades didáticas, em que pode-se utilizar o Método de Resolução de Problemas (MRP), para encontrar soluções, e assim ensinar os conteúdos propostos às séries do Ensino Médio (EM).

Além disso, conclui-se também que o principal objetivo deste trabalho foi atingido, uma vez que, foi definido como desenvolver um modo de utilizar o MRP no contexto da Coleta Seletiva da Microrregião de Bragança Paulista.

Também, foi realizado um levantamento de referenciais teóricos que embasaram a pesquisa, e também, foi realizada a coleta e triagem de dados da Microrregião de Bragança Paulista, que embasaram as atividades didáticas.

Outra conclusão importante, refere-se no potencial encontrado nas atividades em promover uma reflexão sobre a questão da produção de resíduos sólidos, como, por exemplo, no item 4.2.5, onde informa que apenas 7,35\% dos resíduos coletados em 2013, no município de Atibaia, são reciclados, um dado que acompanhado dos cálculos torna-se mais alarmante ainda, pois concluiuse que em 2013 quase 40 mil toneladas não foram reciclados.

Por fim, também concluísse que frente as dificuldades que educação enfrenta, os professores devem buscar meios de atingir seus objetivos, e o MRP mostrou-se um excelente mecanismo para explorar as soluções de problemas, inclusive para os problemas criados, que são pouco tratados no meio escolar.

\subsection{CONSIDERAÇÕES FINAIS}

Os dados coletados foram trabalhados com o propósito de tornarem-se úteis para conteúdos do EM, no entanto, os mesmos dados podem servir para criar situações distintas e com propósitos diferentes.

Neste caso, o professor deve atentar-se a duas questões, o perfil da turma e o que quer ensinar. No primeiro aspecto, deve analisar qual a melhor maneira de chamar a atenção dos alunos, se é por meio de materiais manipulativos, gráficos e tabelas, visita técnica, enfim, encontrar uma maneira de tornar a utilização do MRP possível. No segundo aspecto, ao definir os problemas, buscar as informações que os subsidiem e torne-os coerentes com a realidade do contexto. As atividades criadas restringem-se ao contexto da Coleta Seletiva e isso proporciona aos alunos uma consciência em relação ao problema de produção dos resíduos sólidos, este que é muito intenso e deve ser trabalhado em sala de aula de diversas maneiras, inclusive com outras disciplinas, sempre é claro, trazendo à tona os conceitos que se intenciona ensinar.

Por outro lado, nem sempre o meio escolar permite inovações didáticas, é comum os professores agarrarem-se a métodos tradicionais, como a resolução de exercícios, o que para Polya (1995), torna o aluno apenas um repetidor e não um pensador de fato.

Ainda assim, o desafio do ensino e da aprendizagem se insere na dosagem precisa da inovação, com o que já existe, sempre na busca do equilíbrio, o qual permita que o aluno acesse o conhecimento sem provocar uma "violência simbólica".

Além disso, a utilização do MRP no contexto da coleta seletiva da Microrregião de Bragança Paulista, permitiu atentar para a sua capacidade de se adaptar a qualquer contexto e permitir o acesso a informação e consequentemente ao conhecimento. 


\subsection{LIMITAÇÕES DA PESQUISA}

Durante a criação das atividades percebeu-se a dificuldade de imaginar o que poderia ocorrer no ambiente da sala de aula, no sentido de não conceber as maneiras possíveis de interpretação dos alunos sobre os problemas e as soluções. Por isto, as resoluções das atividades, apesar de algumas considerarem outras possibilidades, ficaram restritas, e tornam-se mais interessantes com a interpretação dos alunos.

Outra limitação encontrada refere-se aos dados, uma vez que, por se tratarem na grande maioria, de dados estatísticos limitam as possibilidades de conteúdos matemáticos que poderiam ou gostariam de ser tratados. Por outro lado, sempre é possível direcionar um conceito ou conteúdo matemático a novas informações, como no caso dos itens 4.2.1 e 4.2.2, os quais necessitaram de dados mais precisos.

\subsection{PROPOSTA DE TRABALHOS FUTUROS}

O contexto da Coleta Seletiva da Microrregião de Bragança Paulista revelou-se fértil para o desenvolvimento das atividades didáticas, no entanto, ainda é um assunto pouco divulgado e discutido dentro das salas de aula.

Assim, uma proposta de trabalho futuro é a aplicação dessas e outras atividades, oriundas do contexto da coleta seletiva, em salas de aulas, para verificar sua eficácia no aprendizado dos alunos em conceitos matemáticos.

Além disso, se estabelece uma outra proposta de trabalho futuro que é trabalhar a integração com outras temáticas em disciplinas de outras áreas, tais como: Biologia, Química, Física e Geografia; e, consequentemente, promover um projeto, que integre-as e alerte a comunidade escolar sobre os problemas da produção de resíduos sólidos e a importância que a Matemática tem na solução. 


\section{Capítulo 6}

Referências 


\section{REFERÊNCIAS}

[1]. B\&B Engenharia Ltda. Plano Municipal de Saneamento Básico e Plano Municipal de Gestão Integrada de Resíduos Sólidos do Município de Bragança Paulista-SP. Bragança Paulista: B\&B Engenharia Ltda., 2015. vol. 1. 347p. Disponível em: $\quad<$ http://www.braganca.sp.gov.br/v2/wpcontent/uploads/2014/11/P07-Volume-I_PMSB-ePMGIRS_Bragan\%C3\%A7a-Paulista.pdf>. Acesso em: 4 nov. 2016.

[2]. BRASIL, Constituição da República Federativa do Brasil (1988). Lex: Legislação Federal e Educação. Disponível em: <http://www.planalto.gov.br/ccivil_03/constituicao/c onstituicaocompilado.htm>. Acesso em: 28 ago. 2016 .

[3]. _ IBGE. Cidades: Dados gerais. 2016a. Disponível em: <http://cidades.ibge.gov.br/v3/cidades/municipio/3 504107>. Acesso em: 12 dez. 2016.

[4]. IBGE. Cidades: Dados gerais. 2016b. Disponível em: $<$ http://cidades.ibge.gov.br/v3/cidades/municipio/3 507605>. Acesso em: 12 dez. 2016

[5] IBGE. Cidades: Dados gerais. 2016c. Disponível em: <http://cidades.ibge.gov.br/v3/cidades/municipio/3 523404>. Acesso em: 12 dez. 2016.

[6] Lei no 11.445 , de 05 de janeiro de 2007. Lex: Política Nacional de Saneamento Básico. Disponível em: < https://www.planalto.gov.br/ccivil_03/_ato20072010/2007/lei/l11445.htm>. Acesso em: 10 out. 2016 .

[7]. Lei $\mathrm{n}^{\circ}$ 12.305, de 02 de agosto de 2010. Lex: Política Nacional de Resíduos Sólidos. Disponível em:

http://www.planalto.gov.br/ccivil_03/_ato2007-

2010/2010/lei/l12305.htm>. Acesso em: 12 out. 2016.

[8]. Ministério da Educação. Diretrizes Curriculares Nacionais para o Ensino Médio.

[9]. Ministério da Educação. Secretaria de Educação Média e Tecnológica. Parâmetros Curriculares Nacionais (Ensino Médio). Brasília: MEC, 2000. Disponível em: $<$ http://portal.mec.gov.br/seb/arquivos/pdf/ciencian .pdf>. Acesso em: 20 jun. 2016.

[10]. Ministério da Educação. Secretaria de Educação Média e Tecnológica. Parâmetros Curriculares Nacionais (Ensino Médio). Brasília: MEC, 2002.

[11]. Medida Provisória ำ 746, 2016. Política de Fomento à Implementação de Escolas de Ensino Médio em Tempo Integral. (Em Tramitação).

[12]. BERTOLUCCI, Rodrigo S. Respondendo à Pergunta: porque ensinar matemática na escola básica? 2011. 161f. Dissertação (Mestrado em Educação Matemática). Instituto de Geociências e Ciências Exatas, Universidade Estadual Paulista "Júlio de Mesquita Filho", Rio Claro.

[13]. BONATTO, A.; BARROS, C. R.; GEMELI, R. A.; LOPES, T. B.; FRISON, M. D. Interdisciplinaridade no Ambiente Escolar. Anais... IX ANPED SUL, Canoas, 2012.

[14]. BRINGHENTI, J. R.; GÜNTHER, W. M. R. Participação Social em Programas de Coleta Seletiva de Resíduos Sólidos Urbanos. Revista Engenharia Sanitária, v. 16, n. 4, p. 421-430, out/dez. 2011.

[15]. CLEMENT, Luiz; TERRAZAN, Eduardo A. Atividades Didáticas de Resolução de Problemas e o Ensino de Conteúdos Procedimentais. Revista Eletrónica de Investigación em Educación em Ciencias, v. 6, n. 1, p. 87-101, jul. 2011.

[16]. COSTA, M. V.; MOMO, M. Sobre a "Conveniência" da Escola. Revista Brasileira de Educação, v. 14, n. 42, set/dez. 2009.

[17]. D'AMBROSIO, Beatriz S. Como Ensinar Matemática Hoje? temas e debates. SBEM, Ano II, n. 2, p. 15-19. Brasília. 1989.

[18]. DUARTE, P. C. X. Caracterizando os Temas Transversais e Incentivando sua Utilização nas Aulas de Matemática. Revista Nucleus, v. 8, n. 2, p. 369-379, out. 2011.

[19]. Felco Faleiros Projetos e Consultoria em Engenharia Ltda. (EPP). Plano Municipal de Coleta Seletiva de Atibaia-SP. Atibaia: Felco Faleiros Projetos e Consultoria em Engenharia Ltda., 2015. 145 p. Disponível em: $<$ http://www.saaeatibaia.com.br/PMGIRS_PMCS.ph p>. Acesso em: 3 nov. 2016.

[20]. FERNANDES, M. C. M. Projetos Ambientais na Escola Pública e sua Relação com o processo Ensino Aprendizagem de Matemática. 2010. 135f. Dissertação (Mestrado em Educação em Ciências e Matemática). Faculdade de Física, Pontifícia Universidade Católica do Rio Grande do Sul, Porto Alegre.

[21]. GAROFOLO, A. C. S.; TORRES, T. Z.; COSTA, F. A. Implantação da Coleta Seletiva na Cidade de Cosmópolis, São Paulo: qualidade e sustentabilidade. Anais ... II Congresso Internacional de Ciudades Creativas, Madrid, 2011.

[22]. GIL, Antônio Carlos. Como Elaborar Projetos de Pesquisa. 6.ed. São Paulo: Atlas, 2017. $192 \mathrm{p}$.

[23]. JACOBI, Pedro R.; BESEN, Gina R. Gestão de Resíduos Sólidos em São Paulo: desafios da sustentabilidade. Revista Estudos Avançados, v. 25, n. 71, p. 135-158, fev. 2011

[24]. JUNQUEIRA, S. M. S.; MANRIQUE, A. L. Reformas Curriculares em Cursos de Licenciatura 
em Matemática: intenções necessárias e insuficientes. Revista Ciência \& Educação, v. 21, n. 3, p. 623-635, 2015.

[25]. LORDÊLO, J. A. C.; DAZZANI, M. V. (Orgs.). Avaliação Educacional: desatando e reatando nós. Salvador: EDUFBA, 2009. 349 p.

[26]. LUIZ, Elisete A. J.; COL, Lidiane. Alternativas Metodológicas para o Ensino de Matemática Visando uma Aprendizagem Significativa. Anais... VI Congresso Internacional de Ensino da Matemática, Canoas, 2013.

[27]. MARCONI, M. A.; LAKATOS, E. M. Fundamentos de Metodologia Científica. 7. ed. São Paulo: Atlas, 2010. 297 p.

[28]. NACARATO, Adair M. O Professor que ensina matemática: desafios e possibilidades no atual contexto. Revista Espaço Pedagógico, Passo Fundo, v. 20, n. 1, p. 11-32, jan./jun. 2013. Disponível em: <www.upf.br/seer/index.php/rep>. Acesso em: 10 ago. 2016.

[29]. N S Engenharia Sanitária e Ambiental S/S Ltda. (EPP). Plano Municipal de Saneamento Básico e Plano Municipal de Gestão Integrada de Resíduos Sólidos do Município de Itatiba-SP. Itatiba: N S Engenharia Sanitária e Ambiental S/S Ltda., 2016. vol. 1. 387p. Disponível em: <http://www.itatiba.sp.gov.br/templates/midia/secre tarias/meio_ambiente/audiencia/relatorio_final__volume_i_-_itatiba.pdf>. Acesso em: 5 nov. 2016.

[30]. OGLIGARI, Lucas N. Educação Matemática Crítica e Subcidadania. Anais eletrônicos... IX ANPED SUL, Caxias do sul, 2012. Disponível em: <http://www.ucs.br/etc/conferencias/index.php/anp edsul/9anpedsul/paper/viewFile/87/268>. Acesso em: 10 ago. 2016.

[31]. OLIVEIRA, T. B.; JUNIOR, A. C. G. Planejamento Municipal na Gestão dos Resíduos Sólidos Urbanos e na Organização da Coleta Seletiva. Revista Engenharia Sanitária, v. 21, n. 1, p. 55-64, jan/mar. 2016.

[32]. OLIVEIRA, C. M. S.; VAZ, D. A. F. As Implicações do Desenvolvimento da Ciência e Tecnologia na Sociedade, na Escola e na
Educação Matemática da Contemporaneidade. Revista Sapiência: sociedade, saberes e práticas educacionais, v.3, n. 2, p.132-142, jul/dez. 2014.

[33]. PIANA, M. C. A Construção do Perfil do Assistente Social no Cenário Educacional. São Paulo: Editora UNESP, Cultura Acadêmica, 2009. $233 \mathrm{p}$.

[34]. POLYA, G. A Arte de Resolver Problemas: um novo aspecto do método matemático. Rio de Janeiro: interciência, 1995. 196 p.

[35]. RODRIGUES, W.; SANTANA, W. C. Análise Econômica de Sistemas de Gestão de Resíduos Sólidos Urbano: o caso da coleta de lixo seletiva em Palmas, TO. Revista Brasileira de Gestão Urbana, v. 4, n. 2, p. 299-312, jul/dez. 2012.

[36]. SANTOS, F. C. G.; FLEITH, D. S. Efeitos de um Programa de Criatividade para Professoras em Alunos do Ensino Fundamental. Revista Estudos de Psicologia, v. 32, n. 4, p. 755-766, out/dez. 2015.

[37]. SILVA, Edna Lúcia; MENEZES, Estera Muszkat. Metodologia da Pesquisa e Elaboração de Dissertação. 4. ed. Florianópolis: UFSC, 2005. $138 \mathrm{p}$.

[38]. SOUZA, V. O.; LACERDA, C. C. O.; SILVA, E. F. S.; SILVA, L. B. Práticas Ecológicas e Coleta Seletiva na Universidade Estadual da Paraíba. Revista de Administração, Contabilidade e Sustentabilidade, v. 3, n. 3, Ed. Especial, p. 83-98, 2013.

[39]. SOUZA, M. T. S.; PAULA, M. B.; SOUZAPINTO, H. O Papel das Cooperativas de Reciclagem nos Canais Reversos de Pós-consumo. Revista de Administração de Empresas, v. 52, n. 2, p. 246-262, mar/abr. 2012.

[40]. SOUZA, João Carlos. Reciclagem e Sustentabilidade Social: a importância dos processos logísticos. Revista Transportes, v. 19, n. 1, p. 43-48, 2011.

[41]. TERRADAS, Rodrigo Donizete. A Importância da Interdisciplinaridade na Educação Matemática. Revista da Faculdade de Educação, Ano IX, n. 16, p. 95-114, jul/dez. 2011. 
Apêndices 
APÊNDICE A - QUESTIONÁRIO DE LEVANTAMENTO DE DADOS

Questionário encaminhado à cooperativa "Recicle Bragança", por e-mail.

\section{Questionário - Levantamento de dados}

Perguntas:

Quais as dimensões em metros de um fardo prensado?

Quais as dimensões em metros do container utilizado?

Quantos fardos cabem em um container?

Quantos quilos ou toneladas um container suporta?

Quanto pesa em quilos ou toneladas um fardo de:

Papel:

Papelão:

Plástico:

Metal:

Vidro: 
APÊNDICE B - PLANO DE AULA

Disciplina: Matemática $1^{\circ}$ Ano do Ensino Médio

Curso: Ensino Médio

Semestre: 1‥ Sem. 2016

Ano: 2016

Carga Horária Semanal: 04 h/a

Carga Horária: 80 h/a

Professor(a):

Rafael dos Reis Lima de Andrade

\section{Identificação do tema:}

Conceitos de aritmética: "regra de três" simples.

\section{Objetivo:}

Apresentar e analisar os dados da tabela e aplicar o conceito de regra de três simples para obter as porcentagens dos materiais

\section{Pré-requisitos:}

O aluno deve conhecer os conceitos das operações básicas.

\section{Desenvolvimento do tema (Conteúdo Programático):}

Grandezas proporcionais, Grandezas diretamente proporcionais, Grandezas inversamente proporcionais, Regra de três simples.

\section{Metodologia:}

A atividade será desenvolvida com a utilização do Método de Resolução de Problemas, onde devese:

Compreender o problema para identificar as incógnitas;

Fazer um plano com passos lógicos em que se possibilite encontrar as incógnitas;

Colocar o plano em prática; e

Rever os passos e verificar se o resultado está de acordo com o que foi pedido inicialmente;

O conteúdo de aula será desenvolvido por meio de aula expositiva, com análise e discussão dos possíveis caminhos em que se pode tomar par encontrar a solução do problema. Em seguida, propor atividades similares.

\section{Avaliação:}

A avaliação do conteúdo desta aula se dará por meio da:

Verificação do aprendizado deste conteúdo contemplado nas provas mensais/bimestrais;

Entrega dos Atividades requisitadas devidamente realizadas e entregues no prazo. 


\section{BIBLIOGRAFIA BÁSICA:}

[1]. IEZZI, Gelson, DOLCE, Oswaldo e MACHADO, Antonio. Matemática e Realidade. 7. ed. São Paulo: Atual, 2014.

[2]. IEZZI, Gelson; MURAKAMI, Carlos. Fundamentos de Matemática Elementar. v. 1. 8. ed.. São Paulo: Atual, 2013.

\section{BIBLIOGRAFIA COMPLEMENTAR:}

[1]. DANTE, Luiz Roberto. Matemática: contexto e aplicações. v. II. São Paulo: Ática, 1999.

[2]. IEZZI, Gelson; HAZZAN, Samuel; DEGENSZAJN, David. Fundamentos de Matemática Elementar. vol. 11. São Paulo: Atual, 2013.

[3]. IEZZI, Gelson; DOLCE, Oswaldo; DEGENSZAJN, David; PÉRIGO, Roberto; ALMEIDA, Nilze de. Matemática: ciência e aplicações. v. 1. São Paulo: Atual, 2013.
[3]. IEZZI, Gelson; DOLCE, Oswaldo; MACHADO, Antonio. Matemática: volume único. 5. ed. São Paulo: Saraiva, 2011.

[4]. POLYA, G. A Arte de Resolver Problemas: um novo aspecto do método matemático. Rio de Janeiro: Interciência, 1995.

[4]. N S Engenharia Sanitária e Ambiental S/S Ltda. (EPP). Plano Municipal de Saneamento Básico e Plano Municipal de Gestão Integrada de Resíduos Sólidos do Município de Itatiba-SP. Itatiba: N S Engenharia Sanitária e Ambiental S/S Ltda., 2016. vol. 1. 387p. Disponível em: <http://www.itatiba.sp.gov.br/templates/midia/secre tarias/meio_ambiente/audiencia/relatorio_final__volume_i_-_itatiba.pdf>. Acesso em: 5 nov. 2016. 


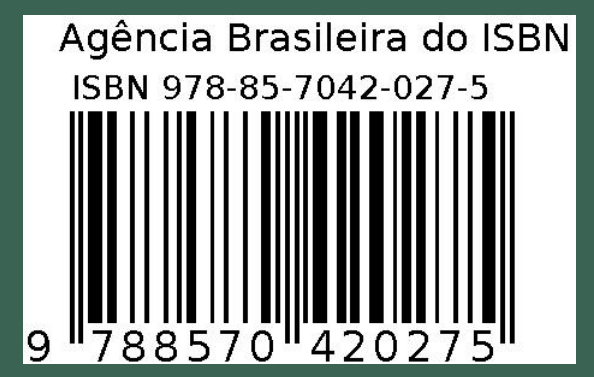

